\title{
CORRUPTION, GOVERNMENT SUBSIDIES, AND INNOVATION: EVIDENCE FROM CHINA
}

\author{
Lily Fang \\ Josh Lerner \\ Chaopeng $\mathrm{Wu}$ \\ Qi Zhang \\ Working Paper 25098 \\ http://www.nber.org/papers/w25098 \\ NATIONAL BUREAU OF ECONOMIC RESEARCH \\ 1050 Massachusetts Avenue \\ Cambridge, MA 02138 \\ September 2018
}

Harvard Business School's Division of Research and the Toulouse Network provided financial support. Wu and Zhang gratefully acknowledge financial support from the National Natural Science Foundation of China (71722012, 71790600, 71790601, 71272082, 71232005, 71402156, and 71532012) and the Major Research Project of Philosophical and Social Sciences of China Education Ministry (15JZD019). Josh Lerner periodically receives compensation for advising institutional investors, private equity firms, corporate venture groups, and government agencies on topics related to entrepreneurship, innovation, and private capital. All errors are our own.

NBER working papers are circulated for discussion and comment purposes. They have not been peer-reviewed or been subject to the review by the NBER Board of Directors that accompanies official NBER publications.

(C) 2018 by Lily Fang, Josh Lerner, Chaopeng Wu, and Qi Zhang. All rights reserved. Short sections of text, not to exceed two paragraphs, may be quoted without explicit permission provided that full credit, including $(\odot$ notice, is given to the source. 
Corruption, Government Subsidies, and Innovation: Evidence from China

Lily Fang, Josh Lerner, Chaopeng Wu, and Qi Zhang

NBER Working Paper No. 25098

September 2018

JEL No. G28,H25,O32

\begin{abstract}
Governments are important financiers of private sector innovation. While these public funds can ease capital constraints and information asymmetries, they can also introduce political distortions. We empirically explore these issues for China, where a quarter of firms' R\&D expenditures come from government subsidies. Using a difference-in-differences approach, we find that the anticorruption campaign that began in 2012 and the departures of local government officials responsible for innovation programs strengthened the relationship between firms' historical innovative efficiency and subsequent subsidy awards and depressed the influence of their corruption-related expenditures. We also examine the impact of these changes: subsidies became significantly positively associated with future innovation after the anti-corruption campaign and the departure of government innovation officials.
\end{abstract}

\section{Lily Fang \\ INSEAD \\ 77300 Fontainebleau, France \\ lily.fang@insead.edu}

Josh Lerner

Harvard Business School

Rock Center 214

Soldiers Field

Boston, MA 02163

and NBER

jlerner@hbs.edu

\author{
Chaopeng Wu \\ Xiamen University \\ China \\ wuchaopeng@xmu.edu.cn
}

\section{Qi Zhang}

School of Management

No.422 Siming Nan Road

Xiamen, Fujian 361005 China

zhangqi19920304@126.com 


\section{Introduction}

R\&D activities are central to economic growth. But $R \& D$ is expensive and frequently engenders large positive spillovers to other entities, which can lead to under-investment by the private sector, as Nelson (1959), Arrow (1962), and many others have noted. As a result, governments frequently subsidize $R \& D$ to incentivize the private sector's investment in this important activity. In an ideal world, these funds can help firms overcome the capital constraints and information asymmetries that might otherwise impede highly uncertain investments into intangible assets.

According to the OECD, all major industrialized nations subsidize $\mathrm{R} \& \mathrm{D}$, ranging from $0.01 \%$ (Chile) to $0.47 \%$ (Russian Federation) of GDP. ${ }^{2}$ In the U.S., which is near the top of this range, the roles of the Defense Advanced Projects Agency in supporting the development of early computer firms and the National Institutes of Health in promoting the fledgling biotechnology industry have been well documented (e.g., Mazzucato, 2013). Similarly, the role of the Israeli Chief Scientist in catalyzing the creation of the nation's high-technology sector has been frequently emulated elsewhere (Senor and Singer, 2009). In recent years, economists have been increasingly interested in understanding the design of public subsidies for innovative firms (e.g., Howell, 2017; Wang, Li, and Furman, 2017).

At the same time, these subsidies can be distorted. The case studies assembled by Cohen and Noll (1991) indicate that political influences can affect the decision to initiate, continue, and terminate public funding for private $R \& D$ projects. These distortions can have deleterious

\footnotetext{
2 Organisation for Economic Cooperation and Development, "Financing Business R\&D and Investment," https://www.oecd.org/sti/outlook/eoutlook/stipolicyprofiles/competencestoinnovate/financingbusinessrdandinnovation.htm.
} 
consequences, leading not only to the misallocation of capital across firms but also to harms to society more generally.

There is a large literature on the economics of corruption, which explores the ways that politically connected firms may exploit government ties to hamper rivals, lighten their own regulatory burdens, obtain financing, and generally maximize firm (though not social) value. (See for example, Khwaja and Mian, 2005, and Akcigit, Baslandze, and Lotti, 2017; Shleifer and Vishny, 1998, provide a thoughtful review.) But the extent of corruption in the allocation of government R\&D subsidies and its implications have attracted relatively little attention from economists, as a review of the major papers in this literature suggests (e.g., Bond, Harhoff, and Van Reenen, 2005; Bronzini and Iachini, 2014; Jaffe and Le, 2015; Lach, 2002; Lerner, 1999; and Wallsten, 2000). This neglect is striking given the importance of innovation for economic growth and the concern that the innovative sector is particularly vulnerable to rent-seeking (Murphy, Shleifer, and Vishny, 1993).

In this paper, we examine the presence of corruption-driven distortions in government subsidies for innovation in China, a natural environment for examining these issues for two reasons. First, innovation has been a focus of intense policy interest in China as a driver for economic growth, as labor costs have soared and infrastructure investments saturated. China's most recent Five-Year Plan, for example, singled out innovation as the key to future economic development. ${ }^{3}$ This policy push has been accompanied by substantial subsidies. According to various issues of the China Statistical Yearbook, between 2005 and 2015, China spent about 1\% of GDP on R\&D

\footnotetext{
${ }^{3}$ Five-year plans are China's top policy blueprints containing its social, economic, and political goals. As the name suggests, each plan covers a five-year period. The $13^{\text {th }}$ Five-Year Plan (the most recent) covers 2016 to 2020. See Apco Worldwide, "The 13th Five-Year Plan: Xi Jinping Reiterates His Vision for China," http://www.apcoworldwide.com/docs/default-source/default-document-library/Thought-Leadership/13-five-yearplan-think-piece.pdf?sfvrsn=2 for information on and analyses of the most recent Five-Year Plan.
} 
subsidies on average. Nearly a quarter of China’s total R\&D spending in 2015 (\$207 billion) was in the form of government subsidies ( $\$ 46$ billion). ${ }^{4}$ These figures are likely understated. For instance, they do not include separate funds for government-backed venture capital investments, which amounted to $\$ 338$ billion in 2015 alone. $^{5}$

Second, a major concern for China's political leaders has been the pervasiveness of corruption. The anti-corruption campaign waged by President Xi Jinping in recent years, which has led to over one hundred thousand prosecutions (including the fall of several "tigers," or senior government officials), provides clear evidence that corruption is rampant in China, a point validated by many outside observers (Pei, 2016). Corruption is a first-order concern when it comes to R\&D subsidies in China because decisions to grant subsidies are typically in the hands of individual government officials rather than peer reviewers and expert panels, as in most western nations. Such a setting creates ample opportunities for government officials to accept bribes and extract rents from firms seeking R\&D subsidies, particularly at the provincial and municipal levels.

The questions that we empirically investigate are:

- How do corruption and firms' innovative capacity affect their ability to obtain government $\mathrm{R} \& \mathrm{D}$ subsidies?

- Are government subsidies associated with firms' future innovation?

We explore three alternative hypotheses concerning the relationship among corruption, government subsidies, and innovation, motivated by the framing of Bertrand et al. (2007). In the first-best world, incorruptible government officials make subsidy decisions based on firms' merits

\footnotetext{
${ }^{4}$ This aggregate $\mathrm{R} \& \mathrm{D}$ subsidy rate (22.2\%) is very close to the average (22.3\%) we calculated from our sample firms' annual reports from 2007 to 2015 (see Table 1's summary statistics).

${ }^{5}$ Shai Oster and Lulu Yilun Chen, "Inside China's Historic \$338 Billion Tech Startup Experiment," https://www.bloomberg.com/news/articles/2016-03-08/china-state-backed-venture-funds-tripled-to-338-billion-in$\underline{2015}$.
} 
(innovative ability). Under this hypothesis, subsidies should be positively related to firms' ability to innovate and unrelated to corruption. If these subsidies significantly reduce capital constraints or provide a signal to future investors (Lerner, 1999), the impact of the subsidies on subsequent innovation should be positive.

Under the second hypothesis, crony capitalism is pervasive, and the allocation of R\&D subsidies is driven entirely by corruption. The more bribes that a firm pays, the more subsidies it receives. A firm's innovative ability has little or no bearing on the amount of subsidies received, and likewise there is little relationship between subsidies and subsequent innovations.

The third hypothesis lies between these two extremes, in line with Bertrand et al.’s (2007) hypothesis that corrupt government subsidies may simply represent wealth transfers that "grease the wheels of commerce.” Government officials may try to allocate subsidies according to merit, but they may also care about private benefits that can be garnered through corruption. Under this hypothesis, both corruption and firms' ability to innovate would lead to more subsidies. The effect of subsidies on future innovation would depend on the relative weight given to merit or corruption by government officials.

To study corruption, we exploit a reporting rule in China that requires firms listed on the domestic A-share exchange to report “Entertainment and Travel Costs” (ETC) as an itemized subcategory of Sales, General and Administrative (SG\&A) costs. Although ETC includes legitimate business expenses, firms and employees have significant latitude in using this line to expense corruption-related expenditures. For instance, banquets held at and gifts purchased from hotels are routinely added to room bills and expensed as business travel expenses. In China, social activities such as eating, drinking, entertainment, and gift-giving that develop "guan xi” (relationships) are the ubiquitous lubricants for business transactions. These activities are among the most visible 
targets of the anti-corruption campaign waged by the Chinese President Xi Jinping beginning in 2012. ${ }^{6}$ Apart from our work, a number of papers in the recent literature have used ETC as a measure of corruption in China. Examples include Cai, Fang, and Xu (2011), Chen, Liu, and Su (2013), and Huang et al. (2017). In Section 2 where we discuss our data in detail, we present a number of tests that validate ETC as a measure of firm-level corruption.

To investigate corruption-related distortions in R\&D subsidies, we undertake differencein-differences analyses, focusing initially on the inception of the anti-corruption campaign in 2012. We explore the changes in the R\&D subsidies offered to the firms that were more or less effective at innovation, as well as those with abnormally high or low ETC expenditures. We also examine the changes in the impact of $R \& D$ subsidies on subsequent innovation.

One concern with such an empirical design is that other factors may have also changed in 2012, which led to shifts in the allocation of subsidies and innovative performance for reasons unrelated to the anti-corruption campaign. To address this concern, we undertake a second difference-in-difference analysis, focusing on the departures of provincial officials responsible for disbursing R\&D subsidies. Routine official job rotations are an integral part of the Chinese Communist Party’s personnel management apparatus. These departures are staggered across time in different provinces, and they can lead to a rapid depreciation for the "guan xi” built up by certain

\footnotetext{
${ }^{6}$ A New York Times article in March 2013 likens the anti-corruption campaign to an austerity measure for the country's elite (https://www.nytimes.com/2013/03/28/world/asia/xi-jinping-imposes-austerity-measures-on-chinas-elite.html). Among other measures, President Xi Jinping required business meals to be limited to "four dishes and a soup". The article reports that $60 \%$ of restaurants surveyed in the two months after the start of the campaign reported reduced business reservations. Sales of shark fin, a Chinese delicacy, dropped by 70\%. Mao Tai, the favorite Chinese spirit in business banquets, also reported slowing sales. The price of the 53-proof Mao Tai, a favorite among business people, fell from a peak of over 2300 RMB in 2012 (roughly US\$380 at the then prevailing exchange rate), to less than 1000 RMB by 2014. See Chinese media reports such as “茅台酒价格或成腐败指数,” http://money.163.com/10/1210/10/6NHKHQRR00253B0H.html and “告别腐败指数 茅台应让老百姓喝得起.” http://business.sohu.com/s2013/others702/ for the price decline of Mao Tai after the anti-corruption campaign.
} 
players which in turn affects subsequent allocation of subsidies. As such, they serve as a strong identification instrument.

We present two main findings. The first involves the determinants of subsidies. Corruption and firms' innovative capabilities both influence the amount of subsidies granted. The two inputs have roughly equal influence: a one standard deviation increase in either variable leads to a roughly $10 \%$ increase in subsidies (as a percentage of revenue) received. However, as depicted in Figures 1 and 2, we find that both the government's anti-corruption campaign and the departures of provincial technology bureau officials sharply altered the relative impact of merit (R\&D efficiency) and corruption on subsidy allocations. Both events increased the influence of merit (firms’ R\&D efficiency) on subsidies and simultaneously reduced the influence of corruption on subsidies. Our regression analyses indicate that the positive impact of R\&D efficiency on subsidies is concentrated in the post anti-corruption campaign and post official departure years. In contrast, while corruption was an important determinant of subsidies before these events, its impact diminished afterwards.

Our second finding highlights the consequences of these changes, which we can examine thanks to the rich data on innovative activity. We find that subsidies became significantly positively associated with future innovation in the years after the anti-corruption campaign and after local official departures, in contrast to the period before these events when this association was largely insignificant. These patterns hold when we use either counts of successful patent applications (either un-scaled or scaled by sales), or citations to measure innovation outcomes constructed using either U.S. or Chinese patent and citation data. They also hold when we use two alternative indicators of innovation outcome: the share of firms' revenue from exports and total factor productivity (TFP). 
Our results are robust to an array of robustness and placebo tests. They are stronger in regions that were more corrupt to begin with, and they are more pronounced for smaller firms and firms that rely more heavily on external financing.

Overall, our findings indicate that anti-corruption efforts reduced the influence that corruption had on subsidy allocation and increased allocational efficiency. Departures of local government officials which abruptly ended the relationships between firms and individual bureaucrats had a similar effect.

The plan of this paper is as follows. In Section 1, we summarize the institutional features and preview the empirical design. Section 2 presents the data employed in the study. Section 3 presents the results on the allocation of subsidies. Section 4 undertakes a series of robustness tests, and Section 5 examines the consequences of these awards. Section 6 concludes the paper.

\section{Institutional Setup and Empirical Design}

The government plays a central role in resource allocation in China, and the allocation of R\&D subsidies is no exception. Since the 1990s, each level of China's government—central, provincial, and municipal—has run bureaus that are responsible for matters related to technology development and innovation. The labyrinth of technology bureaus offers a wide variety of subsidies, including direct monetary subsidies for the development and testing of new products, for major R\&D projects, for the commercialization of new technologies, for small and mediumsized technology enterprises, and for patent application fees and associated costs. The funding source is in each case a combination of central, provincial, and municipal budgetary resources, with the mixture differing with the category of award. While tax credits are also used as a form of 
R\&D subsidy by the Chinese government, we focus on direct, typically discretionary monetary R\&D subsidies in this paper.

The approval process for subsidy applications follows a pyramidal structure. Virtually all applications for R\&D subsidies are initially filed at the municipal level. Applications cannot be submitted at the provincial level unless they have been approved and endorsed at the municipal level, and, likewise, applications cannot be submitted at the central level unless they have been approved and endorsed at the provincial level. As a result, the local (municipal and provincial) technology bureau officials play an important role as gatekeepers and referees of firms' applications. This creates a strong incentive for firms to cultivate good relationships with these local officials, which could include gift-giving and entertaining at the companies' (and ultimately the shareholders') expense.

At the same time, local officials have powerful incentives to select the firms most likely to succeed. An extensive political science literature (e.g., Li and Zhou, 2005) has suggested that officials' future promotion prospects depend on local economic performance in the region for which they are responsible. Career concerns thus create incentives for the government officials responsible for innovation programs to reward the most promising firms.

Consequently, officials' decisions on applications can be affected both by the innovative capability of the company and by the presence of corruption. In order to identify causal relationships between innovative ability, corruption, and subsidies, we rely on exogenous events that allow us to implement a difference-in-differences approach. We exploit two types of exogenous events. The first is the sweeping anti-corruption campaign waged by President $\mathrm{Xi}$ Jinping. While the program officially began with the 18th National Congress in November 2012, at which Xi assumed the reins of power from outgoing General Secretary Hu Jintao (followed by 
the abrupt sacking of Sichuan Deputy Party Secretary Li Chuncheng for abuse of power), these moves were telegraphed by increasing media discussions of corruption and its deleterious impact over the course of 2012.

Figure 3 illustrates the timeline of this event by tracing the frequency of articles in Chinese news media with the phrase "anti-corruption" in the title. ${ }^{7}$ It shows a distinctive and steady increase in media mention of anti-corruption from 2012, the starting year of the campaign. The timing and sweeping nature of this campaign were outside the control of both firm managers and local government officials, making it an exogenous shock to the amount of corruption that firms could engage in. We use this discontinuity to examine the difference in subsidies obtained before and after the anti-corruption campaign, by firms with high and low historical innovative efficiency and firms with high and low amounts of influence activities. To mark a clear separation between the pre- and post-campaign period, we designate the three years before 2012 (i.e., 2009, 2010, and 2011) as the "pre” window and the three years after (2013, 2014, and 2015) as the "post” window. Anecdotes, as well as academic research, indicate that the anti-corruption campaign had a real effect on China's business culture. Apart from the reported significant drops in restaurant bookings, domestic sales in Louis Vuitton stores, and the prices of Mao Tai, a favorite spirit at lavish business banquets, Cao, Wang, and Zhou (2018) report that in 2013 and 2014 alone, over 20,000 government officials and nearly 5,000 other Chinese Communist Party members were punished for violating the new guidelines, and that 59 provincial-level officials were sent to prison for the same reasons. According to Xin Hua News Agency, the Chinese government's official

\footnotetext{
${ }^{7}$ We searched for the key word "anti-corruption" in the titles of all newspaper articles published in all official provincial government newspapers between 2007 and 2014. In China, the media are strictly controlled by the government. Each provincial-level government has an official publication called the "Daily": for example, the Henan Daily and the Shangdong Daily are the official newspapers published by the Henan and Shangdong provincial governments, respectively. Beijing, Shanghai, Tianjin, and Chongqing are four municipalities that enjoy the same administrative status as a province. Publications by these municipal governments (e.g., the Beijing Daily) are also in our sample.
} 
news outlet, there were 80,516 corruption-related cases in 2015, and the average time from the start of the disciplinary inspection to punishment shrank from 253 days in 2014 to 78 days in 2015. A survey conducted by the Anti-Corruption Research Center of the Chinese Academy of Social Sciences, China's leading think tank, indicated that 93.7\% of Communist Party leaders at various levels perceived the government's resolve to catch and punish corruption as "very strong" or "strong." ${ }^{8}$ Zhang (2018) shows that the anti-corruption campaign reduced the likelihood of other types of corporate fraud by nearly $50 \%$.

The second type of exogenous event that we rely on are personnel changes among the local government officials responsible for innovation due to job reassignments by the central government. In China, government postings are frequently reshuffled among the Chinese Communist Party cadres (for a discussion, see Huang, 2002). Strict rules govern the maximum number of years an official can remain at a post. According to the "Party and Government Leading Cadres Selection and Appointment Regulations” put in place in 2002, ${ }^{9}$ technology bureau heads (along with other officials at the same administrative level in the Chinese Community Party's cadre system) are required to step down after a five-year term. In rare cases, appointments can be extended for another term to ten years. Sometimes, special promotions and rotations also occur, leading to sudden, unannounced official departures. ${ }^{10}$

For our purposes, these personnel changes in the local governments offer an ideal context to infer the causal relationship between corruption and subsidies. First, these changes are staggered in different provinces over time, making the identification sharper than the one-off event of the

\footnotetext{
${ }^{8}$ http://www.xinhuanet.com/politics/2016-01/15/c_128630563.htm.

${ }^{9}$ http://renshi.people.com.cn/n/2014/0116/c139617-24132478.html.

${ }^{10}$ The personnel rotation is typically conducted by the secretive Organization Department of the Chinese Communist Party. For instance, Fan, Wang, and Zhu (2011) cite an example in April 2011 in which the leaders of Sinopec, CNOON, and CNPC, China's three largest state-owned oil companies, were simultaneously rotated, to the surprise of the market and even the insiders of these firms.
} 
nationwide anti-corruption campaign. Second, these departures are mandated by Party rules, so they are exogenous to official performance and local economic conditions, and are not under the control of local firms, thus providing an exogenous shock to the relationships between the firms and individual government officials. Last but not least, personal relationships are at the heart of potential corruption: individual government officials both wield the power of the subsidy allocation decisions and stand to gain from corruption. Firms thus have a logical reason to cultivate cozy relationships with local officials. But when a local government official is reassigned and a new official appointed, the relationships between firms and individual officials are severed, which is likely to translate into a reduction in subsidies to firms that have previously engaged heavily in influence activities.

\section{Data and Descriptive Statistics}

Our sample consists of firms that are publicly listed in China's two major exchanges, the Shanghai and Shenzhen A-share markets. In the spirit of Jaffe and Trajtenberg (2002), we focus on firms in the following sectors, which appear to be the most technology-driven and R\&Dintensive (the Chinese Securities Regulation Commission (CSRC) industry codes are in parentheses): petro-chemicals (C4), electronics (C5), metals and materials (C6), machinery and equipment (C7), pharmaceuticals and biotechnology (C8), and information technology (G). Our sample of firms represents $60 \%$ of China's domestically listed firms and $73 \%$ and $80 \%$ respectively of the total R\&D expenses and patent output by China’s domestically listed companies.

In 2006, the CSRC implemented a new set of reporting and accounting rules (The Accounting Rules of China's Enterprises (2006)), which required listed firms to disclose their annual R\&D expenditures, as well as the amount and the details of government subsidies received. We therefore focus on the period from 2007 to 2015. We collect firms’ R\&D expenditures, as well 
as other financial and ownership data, from their annual reports compiled by WIND, a database similar to Compustat in the U.S.

We now turn to describing the key empirical measures in this paper, including corruption, R\&D subsidies, and innovation, as well as our identification approach.

\section{A. Measuring corruption: Entertainment and Travel Costs}

To measure firm level corruption, we use the Entertainment and Travel Costs (ETC) reported by Chinese firms in the footnotes of their annual statements. One of the first papers to use ETC as a corruption measure was Cai, Fang, and Xu (2011). The authors point out that while ETC contains legitimate business expenses, in practice, there is significant latitude in how executives and employees claim such expenses. For example, Chinese business people regularly bribe government officials with gifts, alcohol, cigarettes, banquets, and Karaoke entertainment. If these products and services are procured at a business hotel, all these expenses can be billed to the room and reported as ETC. The hotel invoices will satisfy the accounting and auditing checks. A more flagrant form of corruption is to issue fake invoices for hóngbāo (cash payments, colloquially known as "red envelopes") to officials and pass off these illegal payments as legitimate expenses.

The raw ETC data offer a useful but imperfect measure of corruption for two reasons. First, significant forms of corruption are not included in this measure, such as schemes where companies purchase goods or services from entities associated with government officials at inflated prices. Despite these omissions, the level of ETC is nonetheless significant. Our data indicate that Chinese firms spent $0.6 \%$ of total revenue on ETC between 2009 and 2012. But ETC spending has dropped significantly since the beginning of the anti-corruption campaign, as Figure 4 indicates.

Second, it is difficult to distinguish legitimate business expenses from corrupt payments. To control for systematic variations in legitimate business costs, we borrow from Cai, Fang, and 
$\mathrm{Xu}$ (2011), as well as the accounting literature on the treatment of discretionary accruals (Kothari, Leone, and Wasley, 2005; Gul, Cheng, and Leung, 2011), and estimate the following crosssectional regression for each industry-year subsample:

$$
\text { ETC }_{i, t}=\gamma_{0}+\gamma_{1} \text { Size }_{i, t}+\gamma_{2} \text { Business In Other Regions } i_{i, t}+\gamma_{3} \text { PerCapGDP } P_{i, t}+\varepsilon_{i, t}
$$

where Size is the firm's total assets, Business In Other Regions is the number of geographical regions where a firm's revenue come from other than the region where the firm is based, ${ }^{11}$ and PerCapGDP is the (log of one plus) per-capita GDP of the firm's home province. We use these three control variables to estimate firms' predicted ETC, which is likely to vary systematically. ${ }^{12}$ We then take the residual from this regression as the abnormal ETC (AETC) incurred by the firm, which we use as the primary proxy for corruption in subsequent analyses.

Although the use of ETC as a measure of corruption has increasingly been established in the literature by papers such as Cai, Fang, and Xu (2011) and Huang et al. (2017), we nevertheless conducted a number of tests to validate ETC as a measure of corruption. We have already highlighted the steep drop in ETC after 2012 in Figure 4. We also conducted an event study of stock returns in the spirit of Lin et al. (2018). Specifically, we examined firms with abnormally high and low amounts of ETC during the ten trading days around (i.e., CAR $[-5,+5])$ December 4, 2012, the date that President Xi Jinping and the Central Committee of the Communist Party of China unveiled the "Eight Rules of the Central Politburo" that described the details of the anticorruption campaign. We found that, after controlling for size and book-to-market ratio, firms with

\footnotetext{
${ }^{11}$ Firms report the regional distribution of their revenues in the annual reports. Chinese provinces are grouped into eight geographic regions: North (华北), South (华南), Middle (华中), East (华东), North-East (东北), North-West

(西北), South-West (西南), and Hong Kong/Macau/Taiwan (港, 澳, 台). Foreign countries are coded as one separate region.

${ }^{12}$ Our results are robust to including additional control variables, such as firm leverage and operating performance (return on assets). They are also robust to using panel regressions, rather than industry-year subsample regressions, to estimate the abnormal ETF. These additional results are available on request.
} 
high (above median) AETC experienced an average -3.96\% market-adjusted abnormal return over the ten trading days, compared to an average abnormal return of $-2.76 \%$ for firms with low (below median) AETC, a difference that is significant at the $10 \%$ level.

Our third test examines the contemporaneous correlation between provincial averages of ETC (computed by averaging across all firms in a province in a given year) with three other provincial-level corruption measures, focusing on the period between 2009 and 2011, i.e., the precampaign years. Results in Panel A of Table 1 indicate that the average ETC is highly correlated with other corruption measures, supporting ETC as a valid measure for corruption.

One related, though separate, concern is that the anti-corruption campaign of President Xi was a politically motivated effort to consolidate power and had little to do with corruption. To examine this, we correlate the provincial levels of ETC/AETC in pre-campaign years of 20092011 with the number of officials punished during the years of 2012-2015. Panel B of Table 1 indicates that these measures are highly correlated, indicating that the anti-corruption campaign was focused on regions of China with higher levels of corruption.

\section{B. $R \& D$ subsidies}

Information on direct monetary R\&D subsidies that firms received from the government is hand collected from the footnotes of firms' annual reports. According to the 2007 Chinese “Company Accounting Principles Rule 16 - Government Subsidies,” firms are required to disclose in the notes of the annual reports the type and amount of such subsidies received from government sources. We read these notes for all firm-years in our sample and calculated R\&D subsidies for each firm-year as the sum of the following seven types of funding:

1) subsidies for product development, intermediate testing, and major R\&D projects; 
2) funding from the national and provincial Small and Medium Technology Enterprises Innovation Funds (also known as InnoFunds);

3) subsidies for small and medium enterprises’ technological adaptation and upgrading;

4) subsidies for technological modification and upgrading;

5) subsidies for technology commercialization and equipment and systems purchase;

6) R\&D grants; and

7) subsidies for patent applications. ${ }^{13}$

Throughout the paper, we calculate the total sum of subsidies each firm receives each year and scale that total amount by firm revenue. (We repeated our analysis using unscaled subsidies; those results are reported in our Internet Appendix in Tables IA4 through IA7.)

Table 2 lists the total amount and the breakdown of these seven categories, and it shows that the most important sources of funds, by far, for our sample of listed firms are R\&D grants (category 6) and subsidies for commercialization (category 5). The InnoFund (category 2), which has attracted academic interest recently (e.g., Wang, Li, and Furman, 2017) represents a very small part of the total subsidies for our sample firms, no doubt because our sample is drawn from large, listed firms, while the InnoFund is ear-marked for small firms, including unlisted ones. ${ }^{14}$

Figure 5, Panel A shows the percentage of our sample firms that receive some R\&D subsidies each year. This percentage increased steadily from about 60\% in 2008 to $95 \%$ in 2015, illustrating the extensive and growing nature of China’s subsidy program. To examine whether

\footnotetext{
${ }^{13}$ The Chinese headings for these categories are: 1) 科技三项费用; 2) 科技型中小企业创新基金; 3) 中小企业创 新资金项目; 4) 技术改造与工业转型升级经费; 5) 产业化经费、以及设备购买、信息化系统、平台建设等其 他经费; 6) 科研项目经费; 7) 专利补贴.

${ }^{14}$ The seven categories are also not equally focused on innovation: for instance, categories 5 and 7, subsidies for commercialization \& equipment purchases and patent applications, might be seen as less directly related to innovation activities. In Tables IA17-IA20 of the Internet Appendix, we separate these funding sources and find that the main results are driven by the funding more directly related to innovation (i.e., categories other than 5 and 7).
} 
China's subsidies favor large firms and state-owned enterprises (SOEs), we looked at trends in new subsidy recipients among smaller firms (firms with below-median market capitalization in a given year) and non-SOEs. As Panels B and C show, subsidies are increasingly available to these firms particularly since 2013, i.e., since the inception of the anti-corruption campaign.

\section{Firms' historical innovative efficiency}

We consider both firms' $R \& D$ inputs and their outputs to construct a historical $R \& D$ efficiency measure, which we use in Tables 3 through 9. We use firms' R\&D expenditures (collected from their annual financial statements) as the measure of R\&D inputs. We use patents to measure firms' innovation output. In the spirit of Hirshleifer, Hsu and Li (2013), we define firms’ R\&D efficiency as the following ratio between innovation output and input:

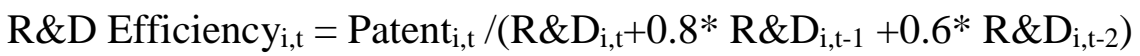

where Patent $\mathrm{i}_{\mathrm{i}, \mathrm{t}}$ is firm $i$ 's new patent applications filed in year $t$ that were approved by the end of 2017; and the $R \& D_{i, t}, R \& D_{i, t-1}$, and $R \& D_{i, t-2}$ are the $R \& D$ expenditures in millions of $R M B$ during year $\mathrm{t}, \mathrm{t}-1$, and $\mathrm{t}-2$.

Our primary patent data come from the Chinese State Intellectual Property Office (CSIPO), China's counterpart to the United States Patent and Trademark Office (USPTO). ${ }^{15}$ CSIPO provides annual information starting from 1985 on each granted patent’s application year, grant year, technological class, number of citations subsequently received, etc. We manually collected information on Chinese patents that were filed before Dec 31, 2016 and that were granted by Dec 31, 2017 from the CSIPO website. The grant-date cutoff is set to be one year later than the application-date cutoff to accommodate the delays associated with patent approvals. We obtained our sample firms’ U.S. patents over the same period (i.e., applications filed by Dec 31, 2016 and

\footnotetext{
${ }^{15}$ http://epub.sipo.gov.cn/gjcx.jsp.
} 
granted by Dec 31, 2017) from the USPTO, cross-checked and supplemented with data from the leading full-text Chinese database on Chinese firms' foreign patents, Innojoy. ${ }^{16}$ U.S. patents are often considered higher quality than Chinese patents, and thus may be a better measure of innovation. However, it is still relatively rare for the firms in our sample to have U.S. patents: while $84 \%$ of our firms had been granted Chinese patents as of the end of 2016, only $15 \%$ of them had been granted U.S. patents. Therefore, we use the Chinese patent data to construct the R\&D efficiency measure, one of our main independent variables. In analyses that focus on future innovative output, we report results pertaining to U.S. patents, though our results are robust if we use Chinese patents, which are reported in Tables IA15 and IA16 in our Internet Appendix.

One concern about the R\&D efficiency measure in Equation (2) is the imprecision with which Chinese firms measure and report their R\&D expenditures. (This concern extends well beyond China; see, for instance, National Research Council, 2005, which discusses this issue for the U.S.). To address this concern, we repeated the analysis using sales rather than R\&D as the scaling variable in Equation (2). These results are reported in Tables IA8 through IA12 of the Internet Appendix.

\section{Firms' future innovative output}

We construct four variables to measure a firm's innovative output, Patents/Sales, Relative Citation Strength, Foreign Sales/Sales, and TFP, which we use in Tables 10 and 11.

Patents/Sales is the number of patent applications filed by a firm in year $t$ that are ultimately granted by the end of 2017, divided by its revenue in year $t$. Our second measure of innovation

\footnotetext{
${ }^{16}$ http://www.innojoy.com/search/home.html. It is important to cross-check and supplement our direct download from USPTO using this dataset because of the high potential for disparities in company names, which are the key identifiers for data matching, and because some companies might register their patents using subsidiary entities. Innojoy is the leading full text, searchable Chinese dataset on Chinese firms' global patents. It is provided by Dawei Technologies, a Chinese technology and software firm and is widely subscribed to by leading Chinese universities and private sector firms.
} 
output is Relative Citation Strength. Our patent citation data is updated through April 30, 2018. We use a citation data cutoff date that is as recent as possible and that falls after the patent grant cutoff date to account for the fact that citations take time to accumulate. For each patent, we calculate its Relative Citation Strength as the number of citations it received up to April 30, 2018, divided by the average number of citations per patent received over the same period by all patents applied for in the same application year $t$ as the patent in question (that are also ultimately granted by the end of 2017) and in the same four-digit technological class. ${ }^{17}$ This is a relative citation strength measure; the scaling controls for the application year and technological class. A Relative Citation Strength higher than one means that a patent is cited more than the average patent successfully filed for in the same year in the same technology class.

For these two patent-based measures of firm's future innovation, we construct two versions, one using the Chinese patent and citation data and one using U.S. patent and citation data. Our results are qualitatively the same using either version. For brevity, we report the results using future U.S. patents and their citations in the paper. Results using Chinese patent and citations are reported in Tables IA15 and IA16 of our Internet Appendix. An issue with these measures is truncation: a relatively small fraction of patents filed in 2016 are likely to have been issued by the end of 2017. To address these concerns, we add year fixed effects in our regressions. It should also be noted that Hall, Griliches, and Hausman (1986) highlight the very short lag between R\&D spending and patent filings.

\footnotetext{
${ }^{17}$ China uses the International Patent Classification (IPC) codes for classifying domestic patents. The U.S. uses the closely related Cooperative Patent Classification scheme. Thus, the subject and scope of the four-digit technology classes in each case are very similar. We use the modal four-digit CPC class to determine the primary patent class assignment in the U.S. If there are multiple classes with the same modal class, we use the earliest listed of these.
} 
As a third measure of innovation outcomes, we use a firm's foreign sales ${ }^{18}$ as a share of total sales, assuming that exports are likely to be of higher quality and more innovative than firms’ domestic offerings. The revenue data are from the WIND database.

Finally, we examine firms' total factor productivity as an outcome variable. We follow Giannetti, Liao, and Yu (2015), and calculate the TFP of each sample firm as the residual from a cross-sectional regression which is estimated annually for each two-digit Chinese industry (using the CSRC industry classification scheme). As explained in more detail in Appendix 1, the dependent variable in the regressions is the natural log of one plus each firm's total annual revenue in year $t$, and the independent variables are the natural log plus one of each of the following contemporaneous measures for each firm: employment, total assets, and total expenditures on labor and capital goods in year $t$.

We again explore the robustness of the results to alternative patent measures — in particular, unscaled patents and those scaled by assets—in Tables IA13 and IA14 of the Internet Appendix.

\section{E. Other variables}

Another variable relevant to our analysis is a firm's ownership type: we distinguish between State Owned Enterprises (SOEs) and private sector firms. SOEs in China enjoy significant advantages in terms of access to bank financing and stock market listings (see, e.g., Dollar and Wei, 2007). Therefore, SOEs may not need to rely as much on government subsidy programs nor to engage in corruption to obtain subsidies. Private sector firms, lacking these financing channels, may have more incentives to compete aggressively for subsidies.

We classify firms' ownership type by tracing their ultimate ownership identified through annual statements. Since 2001, Chinese listed firms are required to report their ownership (equity)

\footnotetext{
${ }^{18}$ Foreign sales do not include sales to Hong Kong, Taiwan, or Macau, which are included as part of Chinese domestic sales.
} 
structure. Following prior literature (e.g., Wang, Wong, and Xia, 2008), we define a company as state-owned if its largest ultimate shareholder is a government entity, which can be a central (e.g., the Ministry of Finance), provincial, or local entity. Otherwise, we define the company as a private enterprise (i.e., if the largest ultimate owner of these firms is either an individual—we aggregate individual investors who are family members—or a private institutional investor). On average, the government ownership stake in the SOEs in our sample is $37.3 \%$.

We are also interested in how firms' political connections affect the subsidies that they receive. ${ }^{19}$ For our sample firms, we manually collected data on the CEOs' and chairmen's political connections from these individuals' profiles in the "Profile of Directors and Senior Managers" section of the firms' IPO prospectuses and annual reports. These profiles typically contain information on the individual's age, gender, education, professional background, and employment history. We coded a firm as politically connected in a given year if the CEO or chairman is currently or was formerly an officer in the central government, a local government, or the military. This definition of political connection is the same as in Fan, Wong, and Zhang (2007).

\section{F. Descriptive statistics}

Table 3 provides summary statistics for our sample, which consists of annual firm-level observations between 2007 and 2015. Panel A reveals several interesting statistics regarding Chinese firms’ R\&D spending and innovation. First, subsidies are an important source of overall R\&D funding, representing $22.3 \%$ of these firms' total R\&D spending. This magnitude almost exactly matches the aggregate figures in the China Statistical Year Book (2016) and suggests that our samples are representative of Chinese firms in terms of subsidies. Second, R\&D spending

\footnotetext{
${ }^{19}$ Khwaja and Mian (2005) and Bao, Johan, and Kutsuna (2015) examine whether political connections affect capital market access in China. The general conclusion is that the market appear able to undo any biases associated with political connections.
} 
(relative to firm size) by our sample firms is similar to that of their U.S. counterparts: In our sample, firms spent 3.7\% of sales on R\&D annually, and in 2013 domestic R\&D spending by U.S. firms was $3.5 \%$ of domestic net sales, including basic industries not in the Chinese sample. ${ }^{20}$ Third, firms spent significant resources on ETC, averaging $0.6 \%$ of annual sales. Since firms received $0.5 \%$ of annual sales as R\&D subsidies on average, if $10 \%$ of the ETC spending was for bribes and corruption, then roughly for each RMB of such ETC spending, firms received 8.3 RMBs of innovative subsidies. The average R\&D efficiency measure was 0.062 , implying that on average it took about 16 (1/0.062) million RMB or 2.4 million USD of R\&D capital to generate one patent. The average relative citation strength for domestic patents is 0.44 . This figure is low (below 1 ) because the table reports unconditional averages, which includes firm-years with zero patents as having zero citation counts. In unreported calculations, we find that the conditional relative citation strength for the patents in our sample is 1.001, indicating that the patents in our sample on average receive the same amount of citations as comparables (patents successfully filed in the same year and technology class), which indicates that our sample is representative of the Chinese patent universe. The unconditional relative citation strength for the firms' U.S. patents is only 0.018 , reflecting that many firms do not have U.S. patents. The conditional U.S. patent relative citation strength for our sample (unreported in the table) is 0.46, meaning that our sample firms' U.S. patents had a citation strength that is slightly less than half of their U.S. counterparts. ${ }^{21}$

Panel B focuses on the relationship between our two main sorting variables, R\&D efficiency and AETC. We are interested in this relationship for both econometric and economic reasons.

\footnotetext{
${ }^{20}$ U.S. National Science Foundation, Business Research and Development and Innovation: 2013 Detailed Statistical Tables, Report no. NSF 16-313, https://www.nsf.gov/statistics/2016/nsf16313/pdf/nsf16313.pdf, Table 19.

${ }^{21}$ The lower relative citation strength of Chinese firms' U.S. patents relative to other comparable U.S. patents could reflect a number of factors: (a) the delays associated with the issuance of foreign patent applications (since the applications are typically filed first at home, and only later in the United States), (b) the likelihood that even after issue, U.S. patents may cite the original Chinese patent, rather than its U.S. counterpart, and (c) a lower technological impact.
} 
Since our subsequent analysis focuses on how these two variables separately and jointly affect subsidies, it is important to understand the correlation between them from an econometric point of view. In terms of economics, the relationship between these two variables should also shed light on whether merit (R\&D efficiency) and corruption (AETC) are complements or substitutes. If they are complements, they would be positively correlated (highly efficient firms spend large amounts on corruption). This suggests a "greasing the wheel" setting whereby efficient firms engage in corrupt behavior as a means of obtaining resources. In such a world, corruption is a transaction cost that could enhance overall efficiency by enabling the funding of efficient firms. If they are substitutes, the two would be negatively correlated (highly efficient firms spend little on corruption and inefficient firms spend a lot). This suggests an environment in which corruption leads to misallocation and is a cost to society. If the two covariates are uncorrelated, then they are neither complements nor substitutes and are simply different firm attributes that can separately influence the allocation of subsidies.

In Panel B, we first report the frequency distribution when we double-sort firms by R\&D efficiency and by AETC. For each firm, we calculate the average R\&D efficiency and AETC for the three pre-campaign years 2009-2011. We then use the median of each variable to independently divide the sample into two halves. The table reports the number of unique firms that fall into each quadrant of the double sort (high efficiency/high AETC, high efficiency/low AETC, etc.). We find that the number of firms in each quadrant was remarkably close: roughly 270 unique firms in each. The Spearman rank correlation was -0.039 with a p-value of 0.197 , not significantly different from zero. Firms' R\&D efficiency and their abnormal ETC spending are thus largely uncorrelated in our sample, indicating that they were independent attributes that separately influenced the subsidy decisions, which we examine next. 


\section{R\&D efficiency, corruption, and government subsidies}

\section{A. Difference-in-differences around the anti-corruption campaign}

We begin by using the anti-corruption campaign to conduct our difference-in-differences analysis. We compare the before-and-after changes in government subsidies received by firms with high or low innovation efficiency and by firms with high or low AETC. For each firm in our sample, we calculate its average R\&D efficiency during 2009, 2010, and 2011, the three years in the pre-campaign window. We use the median of this average to divide the sample firms into highand low-efficiency groups. We likewise divide the sample into high and low AETC groups using data from the pre-campaign period. After the sample formation, we calculate the average amount of subsidies received (scaled by sales) by the high and low efficiency (or AETC) groups both before and after the anti-corruption campaign and compare the increase from before and after across the two groups.

In Table 4, Panel A examines the parallel trends assumption before the anti-corruption campaign by comparing the annual percentage increases in $R \& D$ subsidies received (scaled by sales) in the high- and low- efficiency groups and separately by the high- and low- AETC groups (each calculated during the three pre-campaign years). We do not detect any significant differences in the growth pattern of subsidies received for firms with high and low R\&D efficiency. Likewise, we find no significant differences between firms with high and low AETC spending. Figure IA1 in our Internet Appendix contains a series of plots that examine the parallel trends assumption for key firm-level variables, such as leverage, ROA, and Tobin's Q, and suggest a similar absence of patterns.

Panel B presents the main difference-in-differences analysis for firms with high and low R\&D efficiency. We find that subsidies received by high-efficiency firms increased by over $40 \%$ 
after the anti-corruption campaign, from $0.43 \%$ of revenue to $0.62 \%$ of revenue. Meanwhile, subsidies received by low-efficiency firms showed no significant increase after the anti-corruption campaign, going from $0.51 \%$ of revenue to $0.54 \%$ of revenue. The DiD comparison between the two sets of firms is significant at the $10 \%$ confidence level.

Panel C undertakes a difference-in-differences test for firms with high and low AETC spending before the anti-corruption campaign. ${ }^{22}$ We find that while there was no significant change in the amount of subsidies received by high-AETC firms after the campaign, the amount of subsidies received by low-AETC firms increased by over $50 \%$, from $0.45 \%$ of revenue to $0.70 \%$ of revenue. The difference-in-difference between the two groups is significant at the $1 \%$ level.

Figure 1 depicts the difference-in-differences results by showing the evolution of subsidies received by the different sets of firms over time. Panel A shows the result for firms with high and low R\&D efficiency and reveals a noticeable increase in the subsidies (scaled by sales) received by high-efficiency firms but little change in the subsidies received by low-efficiency firms. The divergence of the two groups became more obvious after 2012. Panel B shows the result for firms with high and low AETC spending. It shows that prior to 2012, high-AETC firms received larger subsidies than low-AETC ones, but the pattern reversed after 2012: subsidies to high-AETC firms dropped, while subsidies to low-AETC firms increased. By the end of our sample, low-AETC firms were receiving larger amounts of subsidies than high-AETC firms.

Overall, the results in Table 4 and Figure 1 indicate that the anti-corruption campaign is associated with a significant re-weighting of merit (R\&D efficiency) and corruption (AETC) in the subsidy-granting decisions. Post campaign, subsidy grants are significantly more sensitive to merit and less sensitive to corruption.

\footnotetext{
${ }^{22}$ Our results are qualitatively similar if we use the raw ETC measure to sort firms.
} 
Table 5 examines these effects in a panel regression setting. Panel A presents the full sample result. The dependent variable is the amount of R\&D subsidies received by a firm in a given year (scaled by the firm's revenue in that year). The key independent variables are R\&D efficiency, AETC, a post-campaign indicator variable, and interaction terms between R\&D efficiency and the post-campaign indicator and between AETC and the post-campaign indicator. All independent variables except the post-campaign indicator variable are lagged by one year.

In models (1) and (2), the interaction terms do not enter the regression; these models evaluate the baseline impact of R\&D efficiency and corruption on subsidies. The results indicate that R\&D efficiency and corruption both have a positive and significant effect on subsidies. The coefficients suggest that a one standard deviation increase in R\&D efficiency is associated with a $10 \%$ increase in R\&D subsidies. ${ }^{23}$ Likewise, a one standard deviation increase in AETC is associated with $9.4 \%$ increase in R\&D subsidies. ${ }^{24}$ Thus, the two variables have roughly equal impacts on subsidies.

Models (3)-(6) include the interaction terms between R\&D efficiency and the postcampaign variable and between AETC and the post-campaign variable. Consistently across the four specifications, we find that the interaction term between R\&D efficiency and the postcampaign indicator is positive and significant, indicating that the effect of efficiency on subsidies is stronger after the campaign. By way of contrast, the interaction term between AETC and the post-campaign indicator is significantly negative across all four models, meaning that the effect of AETC on subsidies weakened after the anti-corruption campaign. These results are consistent with the difference-in-differences results shown earlier. Based on the coefficient estimates of model (6),

\footnotetext{
${ }^{23}$ The standard deviation of R\&D efficiency is 0.169 (Table 3). Given the coefficient of R\&D efficiency is 0.003 , the associated impact on subsidies is $0.0005(0.169 * 0.003)$. Since the average subsidies are 0.005 (Table 3), this means the increase is about $10 \%$ of the average subsidies received.

${ }^{24}$ The calculation parallels that above: $0.008 * 0.059 / 0.005=9.4 \%$.
} 
which includes firm fixed effects, a one standard deviation increase in R\&D efficiency in the postcampaign years is associated with a $10 \%$ increase in $\mathrm{R} \& \mathrm{D}$ subsidies relative to the mean. The R\&D efficiency variable alone is insignificant, indicating that, pre-campaign, it has an insignificant impact on subsidies. In other words, almost all R\&D’s impact comes from the postcampaign period. On the other hand, AETC in pre-campaign years is positively and significantly associated with subsidies, but this association disappears after the campaign, as the sum of the coefficients of the AETC variable and its interaction term with the post-campaign variable is slightly negative $(0.064-0.069)$. Thus, while overall R\&D efficiency and AETC have roughly the same impact on subsidies, there is a reversal in their impact on subsidies post campaign, when R\&D efficiency gained significance and AETC lost significance. These results are consistent with our findings in the difference-in-differences analysis, and they indicate that the anti-corruption campaign had the effect of significantly strengthening the relationship between R\&D efficiency and subsidies and dampening the relation between AETC spending and subsidies.

Other control variables generally have expected signs. For instance, SOEs generally receive fewer subsidies, perhaps reflecting the fact that SOEs are generally better funded and have other channels for accessing state resources. Firms with higher Tobin's Q tend to receive more subsidies and firms with higher leverage tend to receive fewer subsidies. Political connections, on the other hand, do not influence subsidies.

If the changes in subsidy allocations are related to anti-corruption efforts, we expect them to be more pronounced in regions that were ex ante more corrupt. To examine this regional variation, we use the corruption index calculated by China's National Economic Research Institute (NERI). The NERI index is a widely used measure of corruption in China. It is constructed from survey responses on two issues: 1) the time businesses spend dealing with bureaucracy, and 2) the 
non-tax expenses levied on enterprises, including informal charges and illegal fines from the local government, as a percentage of sales. ${ }^{25}$ We use the province-level corruption indices in Fan, Wang, and Zhu (2010, 2011) to calculate each province's average corruption index over the years before the campaign. We then use the median of this variable to split China's provinces into "high corruption" and "low corruption" categories. Panel B reports regression results on these subsamples. For brevity, only key coefficients are reported.

Consistent with our expectations, the main results that subsidies become more (less) sensitive to R\&D efficiency (AETC) are more pronounced in ex-ante high corruption regions. In fact, before the campaign, R\&D efficiency has no significant impact on subsidy allocation in highcorruption regressions (the coefficient is an insignificant -0.0002). But after the campaign, R\&D efficiency has a positive impact on subsidies, as the interaction term between R\&D efficiency and the post-campaign dummy is positive and significant. The economic magnitude is large: The coefficient of 0.01 on the interaction term indicates that a one standard deviation increase in $R \& D$ efficiency is associated with a one-third increase in subsidies in post-campaign years. ${ }^{26}$ In contrast, in the regression for low-corruption areas, we see that R\&D efficiency itself positively predicts subsidies, but the interaction term is insignificant. The results indicate that in less-corrupt regions, R\&D efficiency was always a significant determinant of subsidies, but there was no significant change in this relation after the campaign.

Overall the results in this section indicate that firms’ R\&D efficiency and corruption both had a positive influence on the amount of subsidies they received; a one standard deviation increase

\footnotetext{
25 The NERI indices have been constructed roughly every three years since 2001, but there are gaps. The available reports to date were published in 2001, 2004, 2007, 2010, 2011, and 2017. We use the reports from 2007, 2010, and 2011, as they cover the years prior to the anti-corruption campaign.

${ }^{26}$ Similar to the calculations above, the associated increase in R\&D/Sales here is $0.169 * 0.01$, or about 17 basis points, which is about $1 / 3$ of the average $R \& D /$ Sales of 50 basis points.
} 
in each variable led to about $10 \%$ increase in subsidies. But the anti-corruption campaign resulted in a reversal in importance of the two variables: post campaign, R\&D efficiency became significant, while corruption (AETC) lost much of its significance. Thus, the campaign simultaneously strengthened the relationship between merit (R\&D efficiency) and subsidies and reduced the influence of corruption (AETC) on subsidies.

\section{B. Difference-in-differences around official departures}

The analyses in this section parallel those of the previous section but focus on our second identification strategy, which is based on the departures of provincial technology bureau heads. ${ }^{27}$ The advantage of this identification strategy is that official departures are staggered across time in different provinces and are exogenous to individual firm performance and regional economic conditions. Since official departures rupture the relationships between firms and the individual bureaucrats, we expect a reduction in the influence of corruption on subsidies after these departures. Moreover, as long as the officials' decisions are at least partially merit-based, we should see the impact of R\&D efficiency on subsidies become stronger after the official departures.

We manually compiled information on the departure of provincial technology bureau heads from various online and offline sources, including the official websites of each provincial government and the central government, newspaper reports, and postings and announcements about personnel movements from the Chinese Communist Party's Organization Department. ${ }^{28}$ Over our sample period, we identified 53 cases of official departures ${ }^{29}$ representing changes in 30

\footnotetext{
${ }^{27}$ While it would be interesting to examine the effects of the rotation of municipal technology bureau heads, we could not capture this information in a systematic manner, given the large number of municipalities and the spotty reporting of personnel moves at this level.

${ }^{28}$ The Organization Department is equivalent to the human resources department of the Chinese Communist Party. Our specific search procedure is as follows. We searched for the key words "technology bureau" and "technology head" from the mentioned sources and general web portals. From these records, we constructed a database of the names of the technology bureau heads for each province during our sample period. We then identified departure dates. ${ }^{29}$ Of the 53 departures, 14 (26\%) were due to promotions or lateral moves within the technology administration field. The remaining 39 (74\%) were due to retirements, demotions, corruption-related charges, or moves that caused the
} 
provinces (i.e., all Chinese provinces except for Yunan). In all, these events affected 3694 firmyear observations for the firms located in each of the affected provinces three years before and three years after each departure, or roughly $40 \%$ of the total sample firm-years. Figure 6 plots the number of official departures by year over our sample period and indicates that these events were staggered across time. We also estimated regressions of these departures on the provinces' GDP growth in the year before (reported in Table IA1 of the Internet Appendix) and found that the latter has no explanatory power. This analysis confirms that these departures were not driven by local economic performance, as would be expected, since the departures were typically part of the Chinese government's routine personnel management procedures.

Table 6 shows the results of the difference-in-differences analysis of $R \& D$ subsidies around the departures of provincial technology bureau heads. For each departure event in year $t$, we define the three years before (i.e., $t-1, t-2$, and $t$-3) as the pre-event window, and up to three years, $t+1, t+2$, and $t+3$ as the post-event window (some events may not have three post-event years, as our sample ends in 2015). For each firm affected by an official departure, we calculate its average R\&D efficiency during the three pre-event years and use the median value of this average efficiency to divide the sample into high- and low-efficiency groups. We similarly create high- and low-AETC groups.

Panel A checks the parallel trends assumption. We tabulate, by event year, the average annual percentage changes in subsidies (scaled by sales) received by the high and low R\&D efficiency groups, and separately by the high and low AETC groups. We do not find any significant differences in the pre-event trends between the high and low sub-groups defined by

official to move to another field. In Table IA21 of the Internet Appendix, we show that our results reported below were primarily driven by the latter types of departures, which were more likely to sever the exiting officials' influence. 
either sorting variable. Figure IA2 in our Internet Appendix examines the parallel trends assumption for other key variables and indicates a similar absence of patterns.

Panel B shows the results of the main $\mathrm{DiD}$ analysis for firms with high and low $\mathrm{R} \& \mathrm{D}$ efficiency before official departures. For this analysis, we calculate the average levels of subsidies (scaled by sales) received by the high and low sub-groups before and after the event and compare the increase from before and after across the two groups. From this panel, we see that the amount of subsidies received by high-efficiency firms more than doubled in the three years after official departures, from $0.19 \%$ of revenue to $0.50 \%$, which is significant at the $5 \%$ level. Meanwhile, there is no notable difference in the amount of subsidies received by low-efficiency firms before and after official departures.

Panel C of Table 6 shows the DiD analysis for firms with high and low levels of AETC expenditures before official departures. The empirical approach is identical to Panel B, except that the sorting variable is AETC. The results show that while there is no change in subsidies to high AETC firms after official departures, subsidies to low AETC firms nearly doubled from $0.24 \%$ before to $0.47 \%$ after these departures. Thus, official departures significantly reduced the influence of corruption on government subsidies. Combining the results of Panels B and C, we conclude that official departures resulted in subsidies becoming more sensitive to R\&D efficiency and less sensitive to AETC spending, similar to the results after the anti-corruption campaign.

Figure 2 illustrates these results. In Panel A, we can discern a notable increase in the subsidies to high-efficiency firms and a less prominent increase to low-efficiency firms. Panel B shows a clear increase in subsidies to low-AETC firms and a simultaneous decrease in subsidies to high-AETC firms. 
Table 7 examines R\&D subsidies before and after official departures in a regression setting. The dependent variable is $R \& D$ subsidies scaled by sales. The key independent variables are the firm’s lagged R\&D efficiency, lagged AETC, a "Post Departure” indicator that equals one for up to three years after the departure year of a government official for each firm that is affected (i.e., located in that province), and the interaction terms between the Post Departure dummy and R\&D efficiency and AETC, respectively. The table's organization parallels Table 5, the analysis around the inception of the anti-corruption campaign.

In all regressions, we find that the coefficient of the interaction term between AETC and the post-departure dummy is significant and negative, indicating that corruption had a weaker effect on subsidies after official departures. In terms of magnitude, the coefficients indicate that the effect of corruption on subsidies is essentially negated by departures. For instance, in model (6) with firm fixed effects, the coefficient of AETC is 0.079. But the interaction term between AETC and the post-departure dummy is -0.078 , suggesting that the net effect of AETC on subsidies in the aftermath of departures was close to zero. We note that the coefficients of the interaction term between R\&D efficiency and the post departure indicator are insignificant, indicating that official departures do not increase the sensitivity of grant decisions towards R\&D efficiency; the salient change is mainly a reduced sensitivity to corruption.

Overall, results in this section consistently indicate that events that resulted in a lower likelihood of corruption —-the anti-corruption campaign or government official departures—had the effect of strengthening the impact of merit (R\&D efficiency) on subsidies and reducing the influence of corruption (AETC) on subsidies. In the next section, we examine the robustness of these findings, as well as alternative interpretations. 


\section{Alternative Hypotheses and Robustness Checks}

\subsection{Placebo Test}

One natural concern relates to our first identification strategy, which is based on the anticorruption campaign. The campaign might be contemporaneous with other changes that also affected innovation in China. For example, while we find that high-efficiency firms receive larger increases in subsidies than low-efficiency firms, it is possible that this reflects a general improvement in China's resource allocation over time. Our second identification strategy, which is based on departures of provincial innovation office leaders, is not subject to this concern, as those events are staggered over time.

To address the concern associated with our first identification strategy, we conduct a number of analyses. Our first analysis is a placebo test, in which we repeat the DiD analysis but pretend that the anti-corruption campaign started in a different year. Specifically, we examine three placebo years: 2009, 2010, and 2011. For each of the placebos, we conduct the same DiD analysis as with the actual campaign, namely, we compare the outcomes using the three years before and three years after the placebo year.

Table 8 presents the key regression coefficients for the placebo analysis. The specification is identical to model (5) in Table 5, the panel regression analysis around the anti-corruption campaign. For ease of comparison, the first column repeats the coefficients from Table 5, Panel A, model (5). Recall that the key finding from Table 5 was that the interaction term between R\&D efficiency and the post-campaign dummy was positive and significant, while the interaction term between AETC and the post-campaign dummy was negative and significant: after the campaign, subsidies are more sensitive to R\&D efficiency and less to AETC. These key results are largely absent from Table 8: the key interaction term is not significant in the placebo years of 2009 and 
2010; it is significant at the $5 \%$ level in 2011, which is very close to the actual year of the campaign. The post-campaign coefficient itself is generally positive and significant for all placebo years used, indicating that overall subsidies have increased over time. But the absence of significant interaction effects in the placebo tests suggests that the change in sensitivities of $R \& D$ subsidies to R\&D efficiency and AETC is associated with 2012, the year of the anti-corruption campaign.

Other checks we conducted include adding year fixed effects or using a linear time trend to pick up the overall improvement in resource allocation over time. None of these analyses alter our results qualitatively. These results can be found in Tables IA2 and IA3 of our Internet Appendix. Overall, we conclude that the findings around the anti-corruption campaign are not merely picking up an improvement in resource allocation over time.

\subsection{Do Subsidies Alleviate Financial Constraints?}

Even though we find that both the anti-corruption campaign and local official departures resulted in more subsidies granted to efficient firms, these results do not necessarily imply more effective resource allocation. One alternative interpretation is that officials simply became "lazy" and allocated resources to obvious winners. Such a strategy not only would make them look good but also would help them escape scrutiny from anti-corruption watchdogs who might bark at any sub-par returns on R\&D subsidies. As a result, efficient firms may already have had plenty of resources, while truly deserving yet financially constrained firms remained under-funded.

If changes in subsidy allocation helped relax financial constraints, we should observe that constrained and yet efficient firms enjoy the greatest benefits. To test for this, we augment our analysis by introducing two financial constraint measures. Our first measure is firm size, with small firms considered more likely to be constrained. This is clearly a crude measure. Our second measure considers firms' dependence on external financing, based on Rajan and Zingales (RZ, 
1998). In the spirit of the RZ analysis, we calculate an industry-level dependence on external financing as follows. First, for each firm in our sample, we calculate its average external financing dependence using data from 2009, 2010, and 2011, the three years before the anti-corruption campaign. A firm's dependence on external financing in a given year is the firm's capital expenditure in a given year minus its cash flow from operations divided by capital expenditure. We then calculate an industry-level dependence measure for each of the two-digit CSRC industry codes as the equal-weighted average of the financing dependence measure across all firms in that industry. Finally, we use the median financial dependence in our sample to divide all industries into those that have "high" and "low" dependence on external finance. Sample firms' external finance dependence are then defined by their industry membership. ${ }^{30}$

Table 9 reports regression analyses of the change in subsidies before and after the anticorruption campaign (analogous to the analysis in Table 5) for small and large firms (models (1) and (2)) and for firms with high and low external financing needs (models (3) and (4)). We find that the changes in R\&D subsidy allocations are more pronounced among small firms and firms with higher external financing needs. The coefficients suggest that, among small firms, R\&D subsidies became four times more sensitive to R\&D efficiency after the anti-corruption campaign than they had been: the overall coefficient of efficiency is 0.002 and its interaction with the postcampaign indicator is 0.008 . These coefficients indicate that for small firms, a one standard deviation increase in $R \& D$ efficiency is associated with a one-third increase in $R \& D$ subsidies after the anti-corruption campaign. ${ }^{31}$ Meanwhile, the sensitivity of R\&D subsidies to AETC is

\footnotetext{
${ }^{30}$ While we follow the definitions in RZ (1998) as closely as possible, we do not use U.S. industry data to divide our sample firms. We felt that the financial characteristics of Chinese industries would be sharply different, due both to strategic financial choices (e.g., differing reliance on outsourced components and use of trade credit), and to differing profitability rates.

${ }^{31}$ The sum of the coefficients of the R\&D efficiency variable and its interaction term with the post-departure indicator is $0.002+0.008=0.01$. The standard deviation of $\mathrm{R} \& \mathrm{D}$ efficiency is 0.169 . Therefore, the associated change in Subsidies/Sales is $0.169 * 0.01=0.0017$, which is about one third of the mean Subsidies/Sales (0.005, Table 3).
} 
reduced by over $80 \%$ (the coefficient of AETC is 0.096 , and its interaction term is -0.078 ). Results based on external financing needs are similar both qualitatively and in magnitude. Meanwhile, neither effect is significant among large firms or firms with low external financial needs. These results support the interpretation that the anti-corruption campaign led to greater allocation of $R \& D$ subsidies to financially constrained firms.

\section{Subsidies and Future Innovation}

The previous sections have shown that both corruption and firms' R\&D efficiency positively influence the amount of government subsidies received. In this section, we investigate the association between subsidies and future innovative outcomes. If subsidies become more meritbased after the anti-corruption campaign and official departures, particularly for financially constrained firms, we might expect subsidies to be more strongly associated with future innovation after these events. We should note that our analysis here focuses only on correlation and cannot show whether the subsidies cause subsequent innovations. ${ }^{32}$

To study the association between subsidies and future innovation, we estimate panel regressions of future innovation outcomes. The dependent variables are the four innovation outcome measures defined in Section 2D, namely, Patents/Sales, Relative Citation Strength, Foreign Sales/Sales, and TFP. (The first two sets of reported results use U.S. patent and citations data. Results using Chinese patent and citations data are similar and are reported in Tables IA15 and IA16 of the Internet Appendix.) The key independent variables are the R\&D subsidy in the prior year (scaled by sales), the post anti-corruption campaign indicator (or indicators for local government official departures), and the interactions between the two. Lagged dependent variables

${ }^{32}$ Using internal administrative data —in particular, regression discontinuity analyses of company evaluations—Wang, $\mathrm{Li}$, and Furman (2017) argue that state innovation funds do not cause higher firm-level innovation. 
are included to control for persistence. Because of the relatively short time series since the anticorruption campaign, the lengthy patent application and approval process, and the time lag between patent grants and citations, our patent and citations data have a truncation bias, especially for the post-campaign years. As a partial correction for this bias, we include year fixed effects in our regressions. To avoid co-linearity, the post-campaign indicator is omitted, but its interaction term with the subsidy variable is the key variable of interest for inferences. Since the anticorruption campaign and the official departures appeared to reduce the distortions of corruption, we expect the association of subsidies and innovation to be stronger thereafter.

The analysis of the changes around the anti-corruption campaign is shown in Table 10. In this panel regression, the unit of analysis is an annual observation of each firm in the sample between 2007 and 2015. Panel A examines firms’ subsequent U.S. patenting. First, the coefficient of subsidies is positive and significant in model (1), indicating that subsidies are correlated with more future patents in general. But models (2) through (4) indicate that once the interaction term with the post-campaign indicator is introduced, the subsidies variable loses significance; only the interaction term is positive and highly significant. This indicates that the positive relation between subsidies and future innovation is driven by post-campaign years. In terms of economic magnitude, a one standard-deviation increase in subsidies (as a percentage of sales) is associated with a 54\% increase in the U.S. patenting rate in post-campaign years. ${ }^{33}$

Results in Panel B pertaining to U.S. patent relative citation strength are qualitatively similar. The coefficient of the interaction term between subsidy and post-campaign years in model (4) is a positive 0.76 , while the coefficient of the subsidies variable alone is a negative and

\footnotetext{
${ }^{33}$ The coefficient on the interaction term between Subsidies/Sales and the post-campaign indicator is 0.006 . The standard deviation of Subsidies/Sales is 0.009 (Table 3). Thus, the magnitude of the associated increase in Patents/Sales is $0.006 * 0.009$. Since the average value of the dependent variable Patents/Sales is 0.0001 , in percentage terms the increase is $0.006 * 0.009 / 0.0001=54 \%$.
} 
insignificant -0.44 . Thus, subsidies were associated with stronger U.S. patent citations in the postcampaign era but not before.

Turning to our two alternative innovation measures, results in Panel C indicate that while subsidies in general did not have much association with foreign sales, they had a significantly positive relationship after the anti-corruption campaign. Similarly, Panel D shows that while subsidies were weakly associated with lower TFP in the years before the anti-corruption campaign, the effect reverses in the post-campaign years: the sum of the two coefficients becomes weakly positive. Overall, results in Table 10 provide strong evidence that subsidies are significantly more associated with future innovation post-campaign than pre-campaign.

Table 11 examines the association of subsidies and future innovation before and after government official departures in panel regressions. The analyses parallel those in Table 10. The dependent variables are again the four innovation output measures. The key independent variables are again the $R \& D$ subsidies (scaled by sales) in the year before, the post-departure indicator variable, and the interaction of the two. The variable "Post Departure" is set to one for up to three years after the departure year of a government official for each affected firm. Lagged dependent variables are again included to control for persistence.

The results in Table 11 are consistent with those in Table 10. The interaction term between subsidies and the post-departure indicator is positive and significant in 11 of the 12 regressions, indicating that $\mathrm{R} \& \mathrm{D}$ subsidies are more strongly associated with future innovation after government official departures. The magnitude of the effects is large: Panel A shows that the coefficient of the interaction term between the post-departure dummy and the subsidy measure is larger than the coefficient of the subsidy variable itself, indicating that the association between subsidies and future patenting more than doubles after official departures. The coefficient estimate 
of 0.004 on the interaction term between subsidies and the post departure indicator in all three models imply that a one standard deviation increase in subsidies (as a percentage of sales) is associated with an extra 36\% in patenting after official departures. ${ }^{34}$ Panel B shows that while the coefficient of the interaction term between subsidies and the post-departure indicator is positive and significant, the coefficient of the subsidies variable alone is negative (and insignificant), indicating that subsidies were associated with more patent citations after official departures but not before. Similarly, Panel C shows that, before the departures, there was essentially no relationship between subsidies and foreign sales. After the departures, the subsidies are associated with higher foreign sales. Post-departure subsidies also have a more positive (or less negative) relationship with TFP.

Overall, the results in Table 11 indicate that official departures, which broke the ties between firms and bureaucrats, had an effect similar to the anti-corruption campaign: subsidies became more strongly related to future innovation outcomes. More generally, this section indicates that subsidies were associated with firms' innovative outcomes. This positive effect was further enhanced by anti-corruption efforts and by other events that disrupted the close relationship between firms and individual government officials, a key channel for corruption.

\section{Conclusions}

Using data from China, we investigate the relationship among corruption, government R\&D subsidies, and innovation. Governments all over the world subsidize innovation efforts, and corruption may be a problem facing many of these efforts. Individuals who control the rights to allocate resources ( $R \& D$ dollars) may be subject to corruption, which can distort their allocation

\footnotetext{
${ }^{34}$ Following similar calculations as the previous footnote, $0.004 * 0.009 / 0.0001=36 \%$.
} 
decisions (or the impact may be more benign). China is a fertile testing ground for these issues, given the pervasiveness of innovative subsidies and corruption.

Exploiting the recent anti-corruption campaign in China and the rotations of government officials responsible for provincial innovation programs, we establish that corruption and firms' innovative abilities both affect the allocation of government R\&D subsidies. But the relationship between firms' innovative abilities and subsidies is strengthened by these events, while the relation between corruption and subsidies is simultaneously weakened. Furthermore, the association between R\&D subsidies and future innovation became significantly positive in the years following these events, while this association was weak at best in the years before.

We conclude that anti-corruption efforts and other mechanisms that break up the ties between firms and officials improve the allocational efficiencies of government R\&D subsidies. These measures both increase the sensitivity of subsidy allocation to firms’ innovative ability and appear to be associated with more efficacious subsidy programs. These findings not only demonstrate corruption-related distortions in government R\&D subsidies, but also provide insights into the design of effective R\&D subsidy programs in China and elsewhere around the world. 


\section{References}

Akcigit, Ufuk, Salome Baslandze, and Francesca Lotti, 2017, Connecting to Power: Political Connections, Innovation, and Firm Dynamics, Unpublished working paper, University of Chicago.

Arrow, Kenneth. 1962, Economic Welfare and the Allocation of Resources for Invention. In Richard R. Nelson, editor, The Rate and Direction of Inventive Activity: Economic and Social Factors. Princeton: Princeton University Press, 609-625.

Bao, Xiaolu, Sofia Johan, and Kenji Kutsuna, 2015, Do Political Connections Matter in Accessing Capital Markets? Evidence from China, Emerging Markets Review 29, 24-41.

Bertrand, Marianne, Simeon Djankov, Rema Hanna and Sendhil Mullainathan, 2007, Obtaining a Driver's License in India: An Experimental Approach to Studying Corruption, Quarterly Journal of Economics 122, 1639-1676.

Bond, Stephen, Dietmar Harhoff, and John Van Reenen, 2005, Investment, R\&D and Financial Constraints in Britain and Germany, Annales d'Economie et de Statistique 79-80, 433-60.

Bronzini, Raffaello, and Eleonora Iachini. 2014, Are Incentives for R\&D Effective? Evidence from a Regression Discontinuity Approach, American Economic Journal: Economic Policy 6, 100-134.

Cai, Hongbin, Hanming Fang, and Lixin Colin Xu, 2011, Eat, Drink, Firms, Government: An Investigation of Corruption from the Entertainment and Travel Costs of Chinese Firms, Journal of Law and Economics 54, 55-78.

Cao, Xiaoping, Yuchen Wang, Sili Zhou, 2018, Anti-Corruption Campaigns and Corporate Information Release in China, Journal of Corporate Finance 49, 186-203.

Chen, Yunling, Ming Liu, and Jun Su. 2013, Greasing the Wheels of Bank Lending: Evidence from Private Firms in China, Journal of Banking and Finance 37, 2533-2545.

Cohen, Linda R., and Roger G. Noll, 1991, The Technology Pork Barrel. Washington: Brookings Institution.

Dollar, David, and Shang-Jin Wei. 2007, Das (Wasted) Kapital: Firm Ownership and Investment Efficiency in China, Working Paper 13103, National Bureau of Economic Research.

Fan, Gang, Xiaolu Wang, and Hengpeng Zhu. 2010, NERI Index of Marketization of China's Provinces 2009 Report. Beijing, Economic Science Press.

Fan, Gang, Xiaolu Wang, and Hengpeng Zhu. 2011, NERI Index of Marketization of China's Provinces 2011 Report. Beijing, Economic Science Press. 
Fan, Joseph P.H., T.J. Wong, and Tianyu Zhang. 2007, Politically Connected CEOs, Corporate Governance, and Post-IPO Performance of China's Newly Partially Privatized Firms, Journal of Financial Economics 84, 330-357.

Giannetti, Mariassunta, Guanmin Liao, and Xiaoyun Yu. 2015, The Brain Gain of Corporate Boards: Evidence from China, Journal of Finance 70, 1629-1682.

Gul, Ferdinand A., Louis T.W Cheng, and T.Y. Leung, 2011, Perks and the Informativeness of Stock Prices in the Chinese Market, Journal of Corporate Finance 17, 1410-29.

Hall, Bronwyn H., Zvi Griliches, and Jerry A. Hausman, 1986, Patents and R and D: Is There a Lag?, International Economic Review 27, 265-283.

Hirshleifer, David, Po-Hsuan Hsu, and Dongmei Li, 2013, Innovative Efficiency and Stock Returns, Journal of Financial Economics 107, 632-654.

Howell, Sabrina T. 2017. Financing Innovation: Evidence from R\&D Grants, American Economic Review 107, 1136-1164.

Huang, Yasheng, 2002, Managing Chinese Bureaucrats: An Institutional Economics Perspective, Political Studies 50, 61-79.

Huang, Zhangkai, Lixing Li, Guangrong Ma, and Lixin Colin Xu. 2017, Hayek, Local Information, and Commanding Heights: Decentralizing State-Owned Enterprises in China, American Economic Review 107, 2455-2478.

Jaffe, Adam B., and Trinh Le, 2015, The Impact of R\&D Subsidy on Innovation: A Study of New Zealand Firms, Working Paper 21479, National Bureau of Economic Research.

Jaffe, Adam B., and Manuel Trajtenberg, 2002, Patents, Citations, and Innovations: A Window on the Knowledge Economy, Cambridge, MIT Press.

Khwaja, Asim Ijaz, and Atif Mian, 2005, Do Lenders Favor Politically Connected Firms? Rent Provision in an Emerging Financial Market, Quarterly Journal of Economics 120, 1371-1411.

Kothari, S.P., Andrew Leone, and Charles E. Wasley, 2005, Performance Matched Discretionary Accrual Measures, Journal of Accounting and Economics 39, 163-197.

Lach, Saul, 2002, Do R\&D Subsidies Stimulate or Displace Private R\&D? Evidence from Israel, Journal of Industrial Economics 50, 369-90

Lerner, Josh, 1999. The Government as Venture Capitalist: The Long-Run Effects of the SBIR Program, Journal of Business 72, 285-318.

Li, Hongbin, and Li-An Zhou, 2005, Political Turnover and Economic Performance: The Incentive Role of Personnel Control in China, Journal of Public Economics 89, 1743-62. 
Lin, Chen, Randall Morck, Bernard Yeung, and Xiaofeng Zhao, 2018, Anti-Corruption Reforms and Shareholder Valuations: Event Study Evidence from China, National Bureau of Economic Research, Working Paper No. 22001.

Mazzucato, Mariana, 2013, The Entrepreneurial State: Debunking Public vs. Private Sector Myths. New York: Anthem Press.

Murphy, Kevin M., Andrei Shleifer, and Robert W. Vishny, 1993, Why Is Rent-Seeking So Costly to Growth?, American Economic Review Papers and Proceedings, 83, 409-414.

National Research Council, 2005, Measuring Research and Development Expenditures in the U.S. Economy. Washington, The National Academies Press.

Nelson, Richard R., 1959, The Simple Economics of Basic Scientific Research, Journal of Political Economy 67, 297-306.

Pei, Minxin, 2016, China’s Crony Capitalism: The Dynamics of Regime Decay. Cambridge: Harvard University Press.

Rajan, Raghuram, and Luigi Zingales, 1998, Financial Dependence and Growth, American Economic Review 88, 559-586.

Senor, Dan, and Saul Singer, 2009, Start-Up Nation: The Story of Israel’s Economic Miracle. New York: Grand Central Publishing.

Shleifer, Andrei, and Robert W. Vishny, 1998, The Grabbing Hand: Government Pathologies and Their Cures. Cambridge: Harvard University Press.

Wallsten, Scott J., 2000, The Effects of Government-Industry R\&D Programs on Private R\&D: The Case of the Small Business Innovation Research Program, RAND Journal of Economics 31, 82-100.

Wang, Qian, T.J. Wong, and Lijun Xia, 2008, State Ownership, the Institutional Environment, and Auditor Choice: Evidence from China, Journal of Accounting and Economics 46, 112-134.

Wang, Yanbo, Jizhen Li, and Jeffrey L. Furman, 2017, Firm Performance and State Innovation Funding: Evidence from China’s Innofund Program, Research Policy 46, 1142-1161.

Zhang, Jian, 2018, Public Governance and Corporate Fraud: Evidence from the Recent AntiCorruption Campaign in China, Journal of Business Ethics 148, 275-296. 


\section{Figure 1: R\&D Subsidies Before and After the Anti-Corruption Campaign}

This figure plots the R\&D subsidies (scaled by firm revenue) received by firms before and after the anticorruption campaign. In Panel A, we sort firms by the average R\&D efficiency (calculated as in Equation 2) during the pre-anti-corruption campaign years of 2009, 2010, and 2011. Firms with above (below) median efficiency are classified as high- (low-) efficiency firms. In Panel B, we sort firms by the average abnormal ETC (AETC; calculated from Equation 1) spending during the pre-anti-corruption campaign years of 2009, 2010, and 2011. Firms with above (below) median spending are classified as high- (low-) ETC firms. The vertical bars represent $95 \%$ confidence intervals.

\section{A. Sorting firms by R\&D Efficiency}

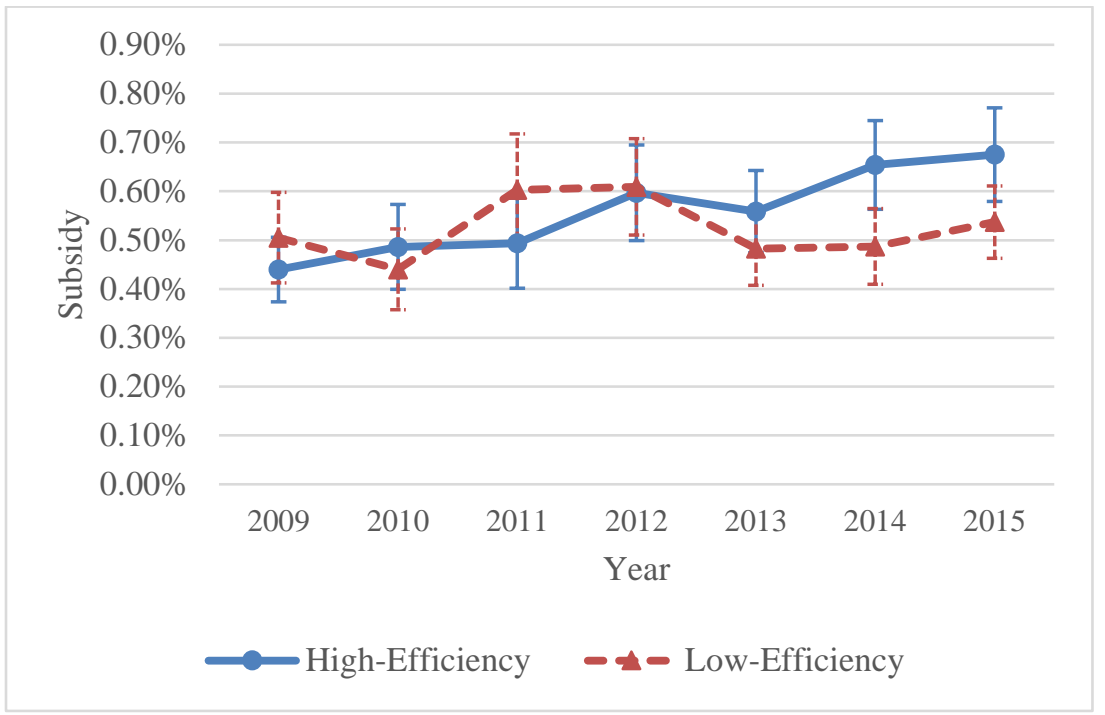

B. Sorting firms by AETC Spending

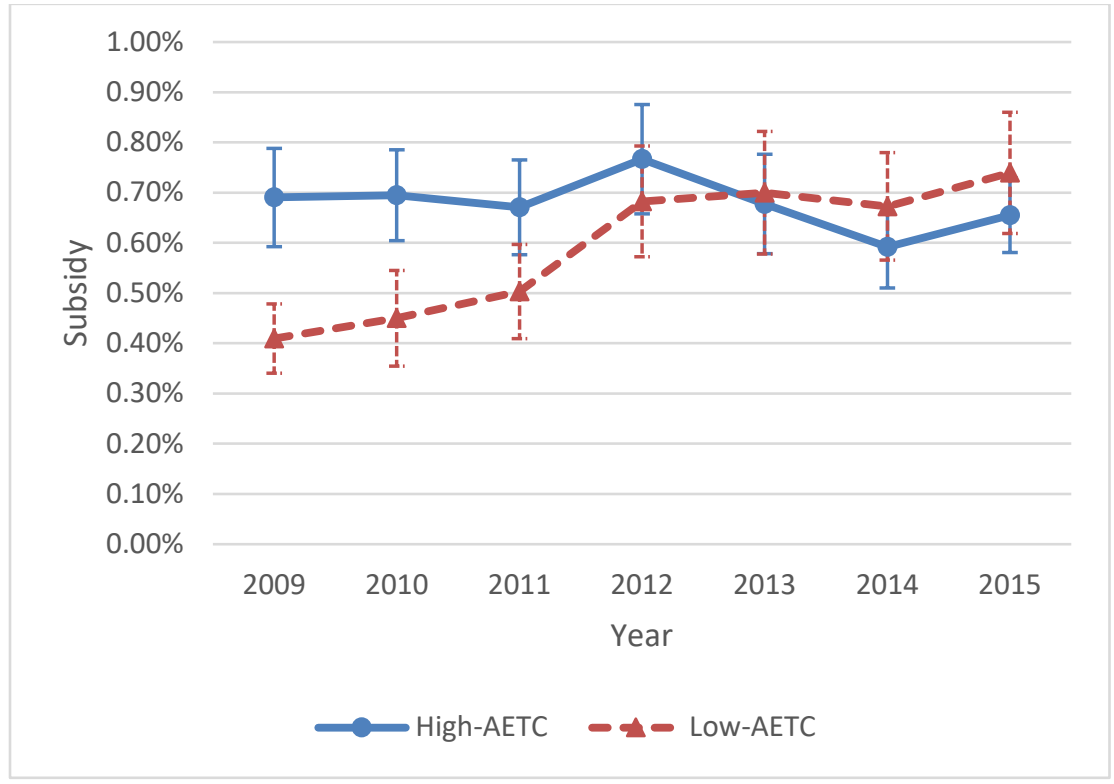




\section{Figure 2: R\&D Subsidies Before and After Official Departures}

This figure plots the R\&D subsidies (scaled by firm revenue) received by firms before and after the departure of provincial technology bureau heads. In Panel A, we sort firms by the average R\&D efficiency (calculated as in Equation 2) during the three event years prior to the official departures. Firms with above (below) median efficiency are classified as high- (low-) efficiency firms. In Panel B, we sort firms by the average AETC spending during the three event years before the officials' departures. Firms with above (below) median spending are classified as high(low-) ETC firms. The vertical bars represent 95\% confidence intervals.

\section{A. Sorting firms by R\&D Efficiency}

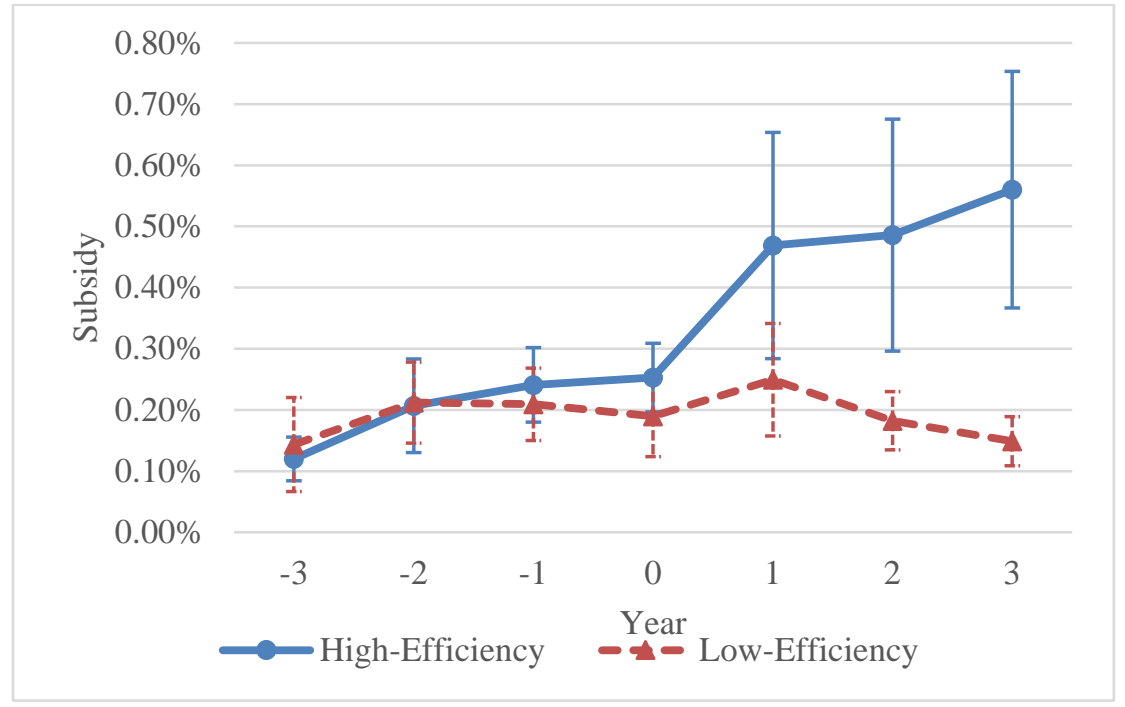

B. Sorting firms by AETC Spending

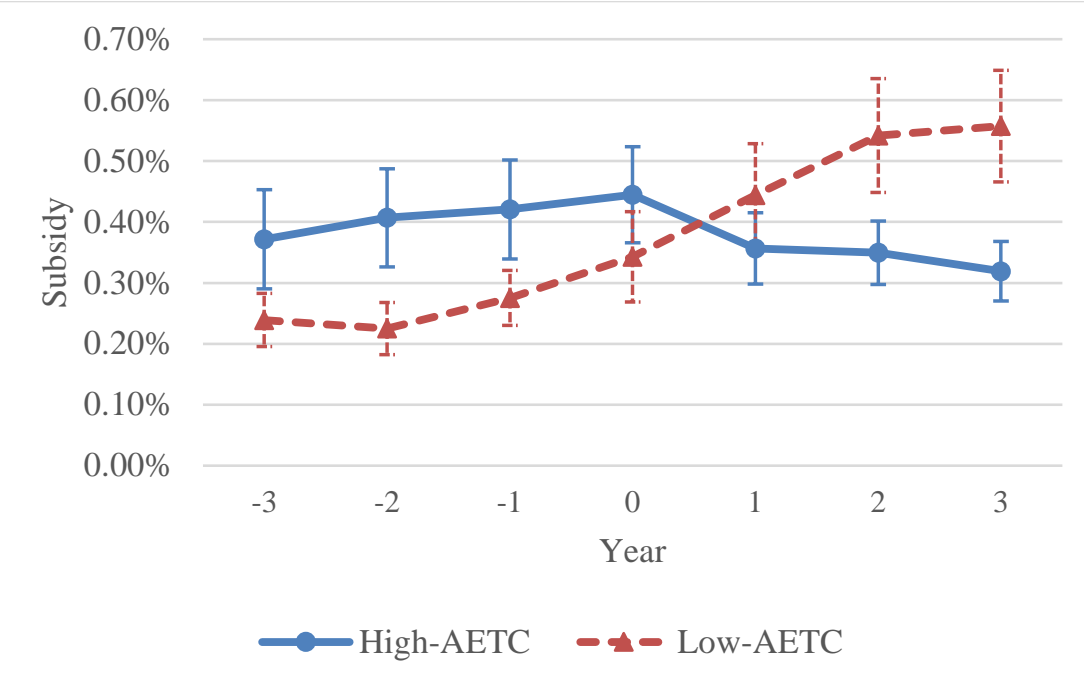




\section{Figure 3: Media Mention of Anti-Corruption}

This graph shows the time trend of the percentage of articles in all official provincial newspapers (the "Daily" newspapers published by provincial governments) with the words "anti-corruption" in their titles. For details on Chinese newspapers, see footnote 7 in the text.

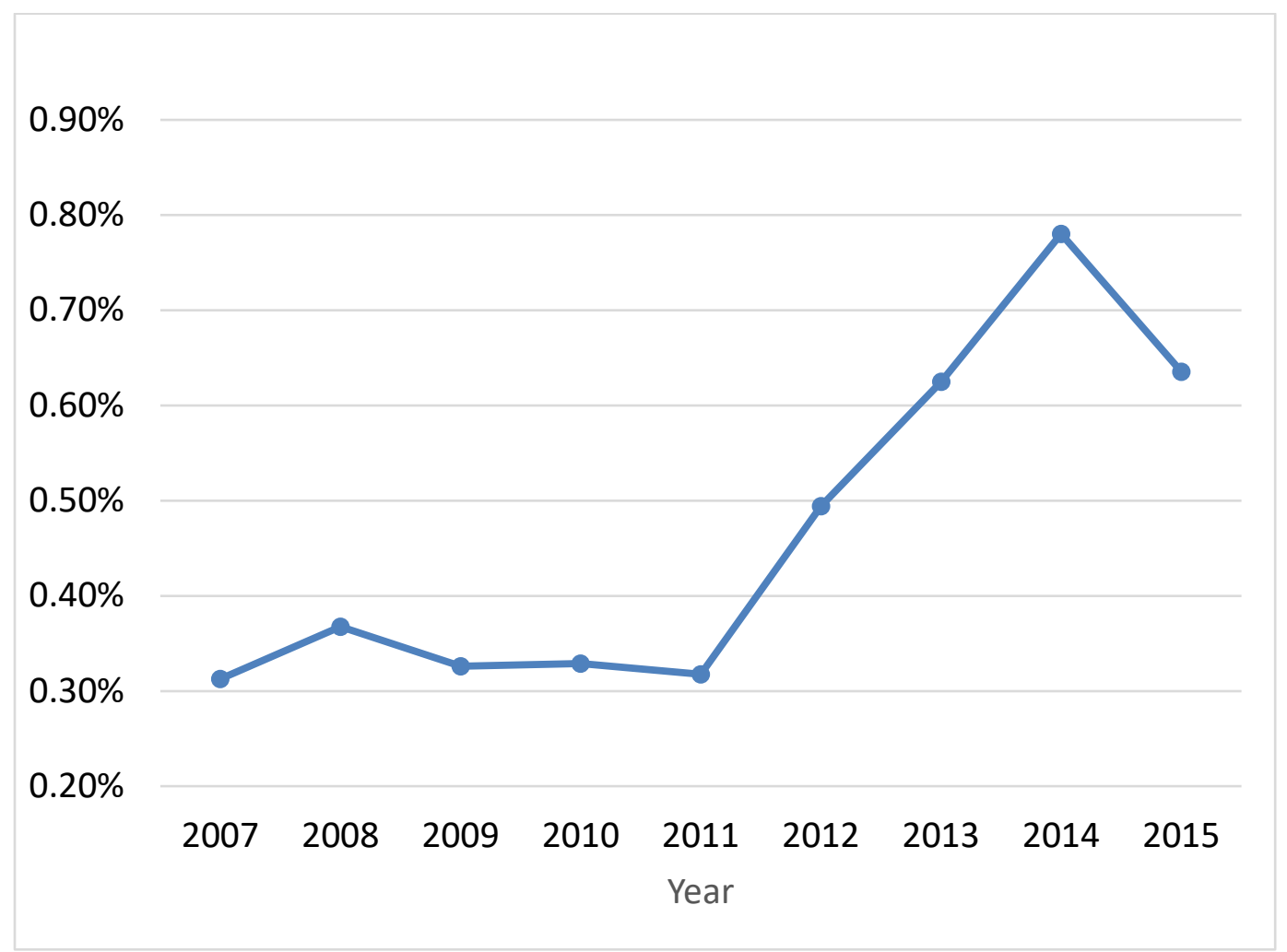




\section{Figure 4: Average ETC Spending Over Time}

This figure shows the trend of the average ETC as a percentage of revenue. ETC is firms' entertainment and travel costs, as reported in their annual statements.

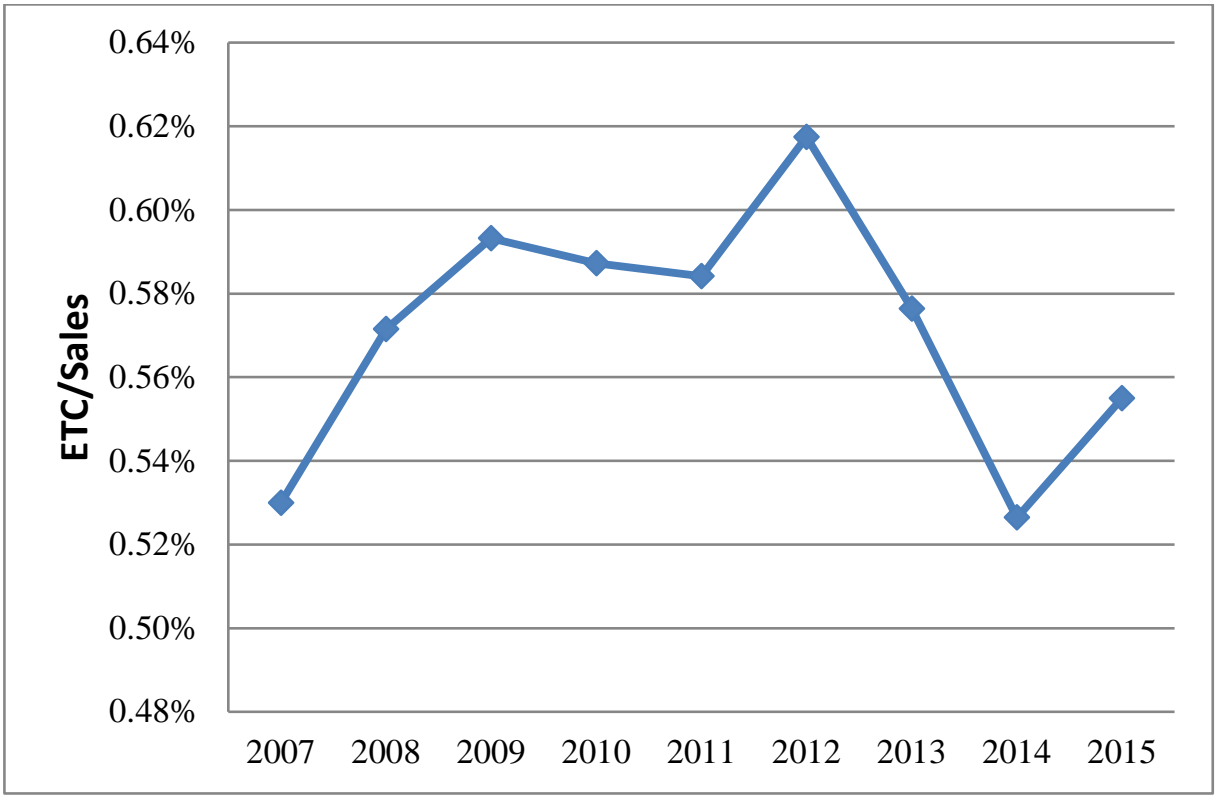




\section{Figure 5: R\&D Subsidies among Sample Firms}

This figure illustrates the extent of Chinese government R\&D subsidies among sample firms. Panel A shows the percentage of firms in our sample that receive subsidies in each year. Panel B shows the percentage of small firms (firms whose total assets were less than the median value in the sample in a given year) among new recipients. Panel C shows the percentage of non-SOE firms among new recipients. SOE classification is detailed in Appendix 1.

A. Percentage of Sample Firms Receiving R\&D Subsidies

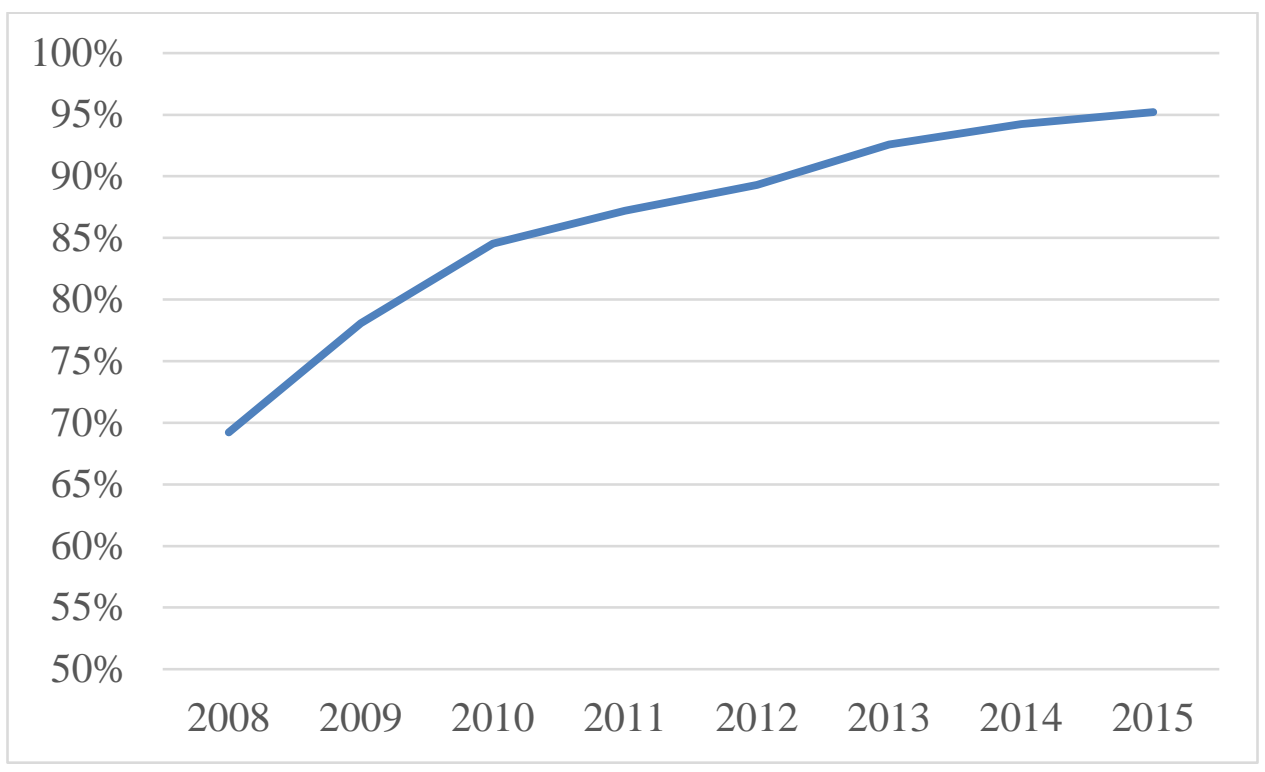

B. Percentage of Small Firms among New Recipients

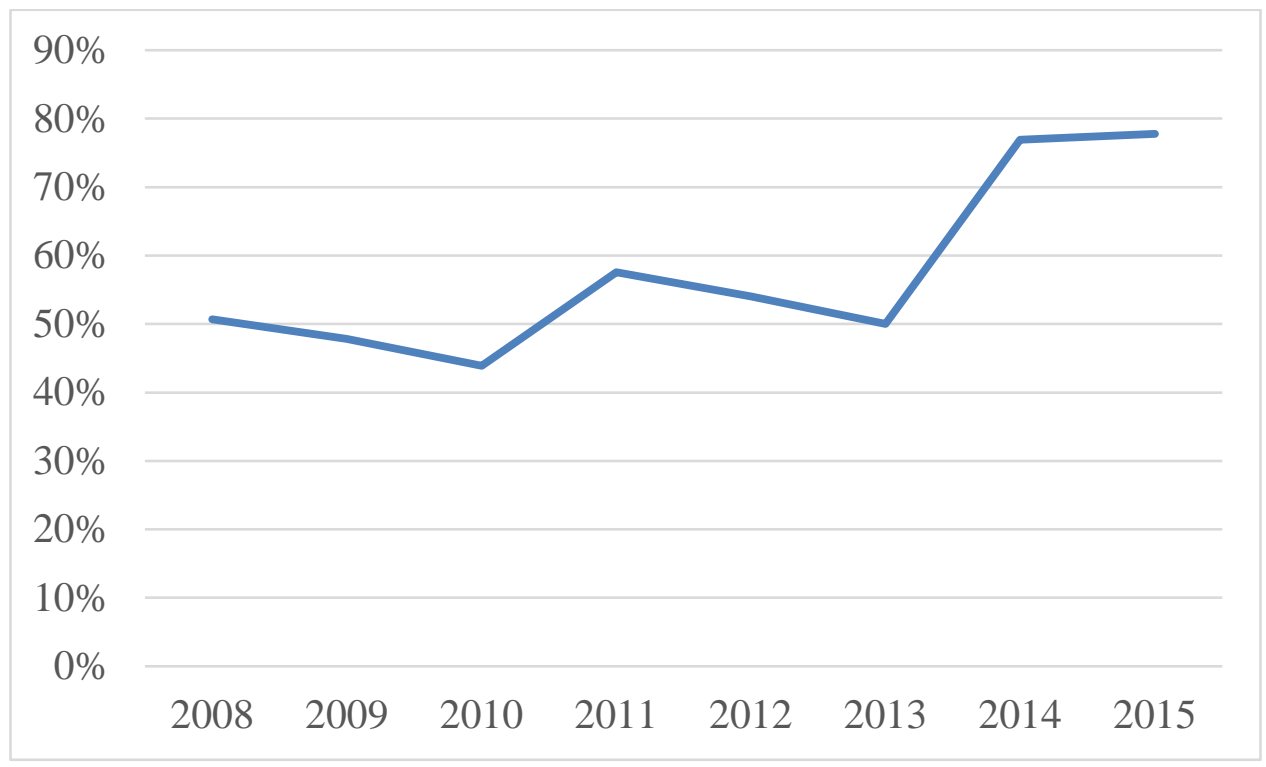


C. Percentage of Non-SOE Firms among New Subsidy Recipients

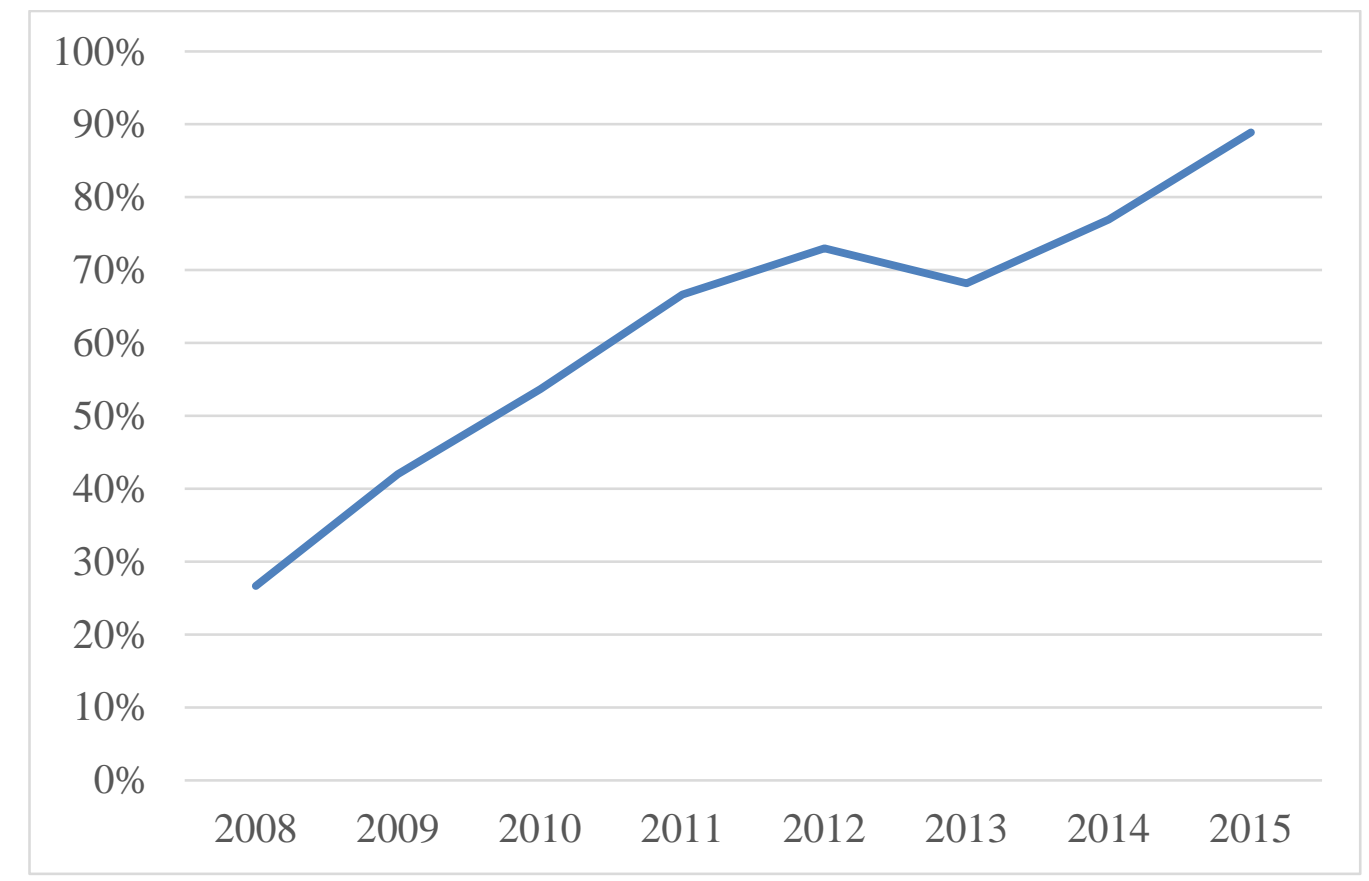




\section{Figure 6: Official Departures over Time}

This figure plots the number of departures of provincial technology bureau heads by year.

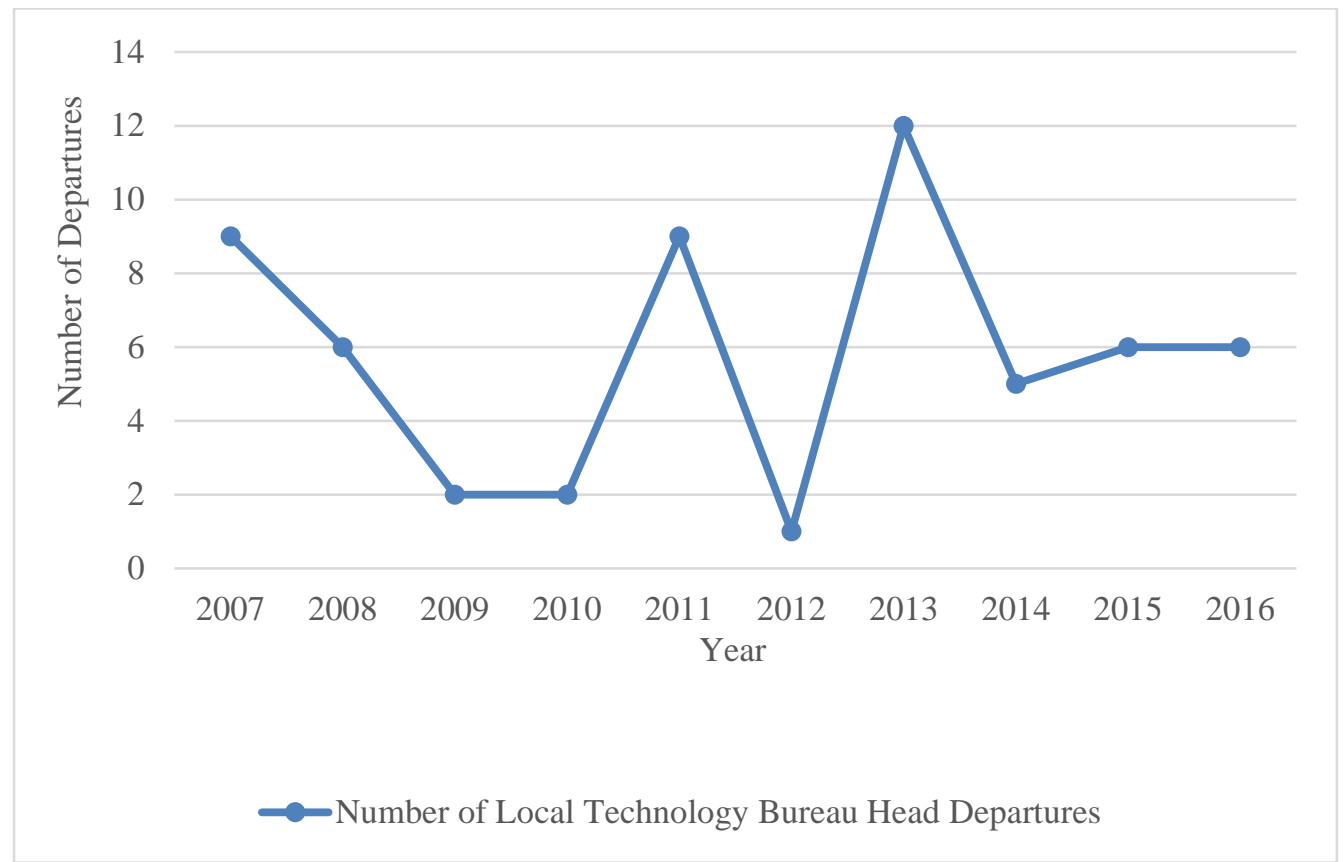




\section{Table 1. ETC and Other Corruption Measures}

Panel A of this table reports the contemporaneous cross-sectional correlation between provincial-year average ETC/sales (and AETC/sales) and three other provincial-year level corruption measures over the period 2009 - 2011 (pre anti-corruption campaign). Corruption Index 1 is the number of government officials prosecuted for corruption each year scaled by the province's population. Corruption Index 2 is the number of white-collar crimes in a province each year scaled by the province's population. The Corruption Control index is an anti-corruption measure (and hence should be negatively correlated with corruption). It is obtained from the Chinese National Economic Research Institute (NERI). The index is constructed from survey responses to two questions: 1) the time spent by businesses in dealing with bureaucracy, and 2) the non-tax expenses levied on enterprises, including informal charges and illegal fines from the local government, as a percentage of sales. Panel B of this table reports the correlation between the pre-campaign (2009-2011) provincial averages of ETC/sales (and AETC/sales) and the number of provincial officials removed due to the anti-corruption campaign (2012-2015) scaled by provincial population.

Panel A: ETC and Corruption in the 2009-11 Period

\begin{tabular}{lccc}
\hline Correlations between: & $\begin{array}{c}\text { Corruption Index 1 } \\
\text { (Officials prosecuted) }\end{array}$ & $\begin{array}{c}\text { Corruption Index 2 } \\
\text { (White Collar Crimes) }\end{array}$ & $\begin{array}{c}\text { Corruption Control Index } \\
\text { (NERI Corruption } \\
\text { Control) }\end{array}$ \\
\hline ETC/sales & $0.161^{* *}(\mathrm{p}=0.048)$ & $0.155^{*}(\mathrm{p}=0.060)$ & $-0.201^{* *}(\mathrm{p}=0.012)$ \\
AETC/sales & $0.251^{* * *}(\mathrm{p}=0.002)$ & $0.288^{* * *}(\mathrm{p}=0.000)$ & $-0.172^{* *}(\mathrm{p}=0.032)$ \\
\hline
\end{tabular}

Panel B: Pre-Campaign (2009-2011) ETC and Corruption in the 2012-15 Period

\begin{tabular}{lc}
\hline Correlations between: & 2012-2015 total number of official removed/population \\
\hline 2009-2011 average ETC/sales & $0.461^{* * *}(\mathrm{p}=0.009)$ \\
2009-2011 average AETC/sales & $0.360^{* *}(\mathrm{p}=0.047)$ \\
\hline
\end{tabular}

\section{Table 2. Categories of R\&D Subsidies}

This table tabulates the seven categories of subsidies that we collected from the companies' financial report footnotes to calculate firms' total subsidies received. We report the aggregate amount and the break-down of these funding sources.

\begin{tabular}{|c|c|c|c|}
\hline $\begin{array}{l}\text { Funding } \\
\text { Category }\end{array}$ & Funding Description & $\begin{array}{l}\text { Total Amount } \\
\text { (Millions RMB) }\end{array}$ & $\%$ of Total \\
\hline 1 & $\begin{array}{l}\text { Subsidies for product development, intermediate testing, } \\
\text { and major R\&D projects }\end{array}$ & 2,123 & $3.15 \%$ \\
\hline 2 & $\begin{array}{l}\text { National and provincial Small and Medium Technology } \\
\text { Enterprises Innovation Funds (InnoFund) }\end{array}$ & 106 & $0.16 \%$ \\
\hline 3 & $\begin{array}{l}\text { Subsidies for small and medium enterprises' technological } \\
\text { adaptation and upgrading }\end{array}$ & 76 & $0.11 \%$ \\
\hline 4 & Subsidies for technological modification and upgrading & 5,577 & $8.29 \%$ \\
\hline 5 & $\begin{array}{l}\text { Subsidies for technology commercialization and } \\
\text { equipment and systems purchase }\end{array}$ & 15,795 & $23.47 \%$ \\
\hline 6 & $\mathrm{R} \& \mathrm{D}$ grants & 43,190 & $64.18 \%$ \\
\hline \multirow[t]{2}{*}{7} & Subsidies for patent applications & 427 & $0.64 \%$ \\
\hline & Total & 67,294 & $100 \%$ \\
\hline
\end{tabular}




\section{Table 3. Descriptive Statistics}

This table provides descriptive statistics of our sample, which consists of annual firm-level observations between 2007 and 2015. Detailed variable definitions are found in the Appendix 1. All financial amounts are measured in millions of RMB. All financial ratios are calculated annually using annual statements. Panel A presents summary statistics and Panel B investigates the relationship between the two key independent variables, R\&D efficiency, and AETC.

Panel A: Sample statistics

\begin{tabular}{lcccccc}
\hline Variable & Mean & Standard Deviation & Min. & Median & Max. & Observations \\
\hline & \multicolumn{7}{c}{ Main Variables } \\
\hline Subsidies/Sales & 0.005 & 0.009 & 0 & 0.002 & 0.064 & 8628 \\
ETC/Sales & 0.006 & 0.009 & 0 & 0.004 & 0.086 & 8628 \\
AETC/Sales & 0 & 0.008 & -0.018 & -0.001 & 0.080 & 8628 \\
R\&D/Sales & 0.037 & 0.044 & 0 & 0.030 & 0.311 & 8628 \\
Subsidy/ R\&D & 0.223 & 0.618 & 0 & 0.071 & 6.401 & 7293 \\
Patent/Sales (China) & 0.004 & 0.009 & 0 & 0 & 0.070 & 8628 \\
Relative Citation Strength (China) & 0.444 & 0.861 & 0 & 0 & 5.641 & 8628 \\
Patent/Sales (U.S.) & 0.0001 & 0.0008 & 0 & 0 & 0.008 & 8628 \\
Relative Citation Strength (U.S.) & 0.018 & 0.137 & 0 & 0 & 1.250 & 8628 \\
R\&D Efficiency & 0.062 & 0.169 & 0 & 0.007 & 1.607 & 8381 \\
Foreign Sales/Sales & 0.144 & 0.210 & 0 & 0.043 & 0.925 & 8628 \\
\hline & & Control Variables & & & 8628 \\
\hline Size (Mil. RMB) & 18451 & 25.36 & 1961.16 & 615319 & 8628 \\
Age (Year) & 5204.41 & 4.843 & 2 & 15 & 37 & 8628 \\
Leverage & 15.47 & 0.235 & 0.030 & 0.400 & 1.567 & 8628 \\
ROA & 0.415 & 0.066 & -0.335 & 0.039 & 0.270 & 8628 \\
Tobin's Q & 0.039 & 2.357 & 0.903 & 2.338 & 18.98 & 8628 \\
Intangible Asset \% & 3.037 & 0.042 & 0 & 0.036 & 0.310 & 8628 \\
SOE & 0.045 & 0.481 & 0 & 0 & 1 & 8628 \\
Political Connections & 0.365 & 0.456 & 0 & 0 & 1 & 8628 \\
Business in Other Regions & 0.296 & 1.217 & 0 & 2 & 8 & \\
\hline
\end{tabular}

Panel B: Relationship between R\&D efficiency and AETC

\begin{tabular}{lcc}
\hline Number of Firms & High Efficiency & Low Efficiency \\
\hline High AETC & 278 & 265 \\
Low AETC & 265 & 278 \\
\hline Spearman rank correlation coefficient between efficiency and AETC: & -0.039 \\
$p$-value for rank correlation coefficient: & 0.197 \\
\hline
\end{tabular}


Table 4. Difference-in-Differences Analysis: Subsidies before and after the Anti-Corruption Campaign

This table conducts a difference-in-difference analysis of the change in R\&D subsidies received by firms with high and low R\&D efficiency (or high and low AETC) before and after the anti-corruption campaign. Subsidies are measured as the amount of R\&D subsidies a firm receives in a given year, divided by its annual revenue in that year. 2009, 2010, and 2011 are pre-campaign years, and 2013, 2014, and 2105 are post-campaign years. We sort firms by the average R\&D efficiency (or average AETC) during 2009, 2010, and 2011. Firms with above (below) median efficiency (AETC) are classified as high- (low-) efficiency (AETC) firms. Panel A investigates the parallel trends assumption in the pre-campaign years by comparing the year-on-year growth in R\&D subsidies (scaled by sales) received by the high and low efficiency (AETC) groups. Panel B (C) reports the difference-in-differences in the levels of R\&D subsidies (scaled by sales) received by firms with high and low R\&D efficiency (AETC) groups. Detailed variable definitions are found in the Appendix 1. *, **, *** indicate statistical significance at the 10\%, 5\%, and 1\% levels in a two-tailed test, respectively.

Panel A: Pre-Trend Test: Annual growth in subsidies/sales

\begin{tabular}{llll}
\hline & 2009 & 2010 & 2011 \\
\hline High R\&D Efficiency & 0.323 & 0.037 & 0.160 \\
Low R\&D Efficiency & 0.528 & -0.101 & 0.247 \\
$t$-stat (High - Low) & -0.109 & 1.465 & -0.867 \\
\hline & & & 2011 \\
\hline High AETC & 2009 & 2010 & 0.134 \\
Low AETC & 0.297 & 0.111 & 0.252 \\
$t$-stat (High - Low) & 0.258 & 0.057 & -1.146 \\
\hline
\end{tabular}

Panel B: Subsidies/sales for firms with high and low R\&D efficiency

\begin{tabular}{lcccc}
\hline & Before & After & After - Before & $t$-stat \\
\hline High R\&D Efficiency & 0.0043 & 0.0062 & 0.0019 & $3.570 * * *$ \\
Low R\&D Efficiency & 0.0051 & 0.0054 & 0.0003 & 0.673 \\
High - Low & -0.0008 & 0.0008 & 0.0016 & $2.200 * *$ \\
\hline
\end{tabular}

Panel C: Subsidies/sales for firms with high and low AETC spending

\begin{tabular}{lcccc}
\hline & Before & After & After - Before & $t$-stat \\
\hline High AETC & 0.0068 & 0.0064 & -0.0004 & -0.684 \\
Low AETC & 0.0045 & 0.0070 & 0.0025 & $3.089^{* * *}$ \\
High - Low & 0.0023 & -0.0006 & -0.0029 & $-2.845^{* * *}$ \\
\hline
\end{tabular}




\section{Table 5. R\&D Subsidies Before and After Anti-Corruption Campaign: Panel regressions}

This table reports panel regression analysis of R\&D subsidies before and after the anti-corruption campaign. Subsidies are measured as the amount of $R \& D$ subsidies a firm receives in a given year, divided by its annual revenue in that year. Panel A presents the results pertaining to the full sample; Panel B presents results when splitting the sample into high and low corruption regions. In Panel B, for brevity, only key coefficients are reported. Detailed variable definitions are found in the Appendix 1. Huber-White heteroskedasticity-consistent standard errors clustered by firm are used for all regressions. $p$-values are in parentheses. *, **, *** indicate statistical significance at the $10 \%, 5 \%$, and $1 \%$ level, respectively.

Panel A: Full sample

\begin{tabular}{|c|c|c|c|c|c|c|}
\hline Dep Var = & $\begin{array}{c}(1) \\
\text { Subsidies } \\
\text { /Sales } \\
\end{array}$ & $\begin{array}{c}(2) \\
\text { Subsidies } \\
\text { /Sales } \\
\end{array}$ & $\begin{array}{c}\text { (3) } \\
\text { Subsidies } \\
\text { /Sales } \\
\end{array}$ & $\begin{array}{c}(4) \\
\text { Subsidies } \\
\text { /Sales } \\
\end{array}$ & $\begin{array}{c}(5) \\
\text { Subsidies } \\
\text { /Sales } \\
\end{array}$ & $\begin{array}{c}\text { (6) } \\
\text { Subsidies } \\
\text { /Sales } \\
\end{array}$ \\
\hline \multirow[t]{2}{*}{ R\&D Efficiency $\mathrm{y}_{\mathrm{t}-1}$} & $0.003^{* * *}$ & $0.003^{* * *}$ & $0.002^{* * *}$ & $0.002^{* * *}$ & $0.002^{* *}$ & 0.0004 \\
\hline & $(0.004)$ & $(0.001)$ & $(0.004)$ & $(0.002)$ & $(0.033)$ & $(0.420)$ \\
\hline \multirow[t]{2}{*}{ AETC $_{t-1}$} & & $0.059^{* *}$ & $0.080^{* * *}$ & $0.078^{* * *}$ & $0.086^{* *}$ & $0.064^{* * *}$ \\
\hline & & $(0.025)$ & $(0.000)$ & $(0.000)$ & $(0.014)$ & $(0.001)$ \\
\hline \multirow[t]{2}{*}{ Post Campaign } & & $0.001^{* * *}$ & $0.001^{* * *}$ & $0.001^{* *}$ & $0.001^{* *}$ & 0.0001 \\
\hline & & $(0.000)$ & $(0.001)$ & $(0.011)$ & $(0.023)$ & $(0.522)$ \\
\hline \multirow[t]{2}{*}{ R\&D Efficiency $\mathrm{t}_{\mathrm{t}-1} \times$ Post Campaign } & & & $0.005^{* * *}$ & $0.005^{* * *}$ & $0.006^{* *}$ & $0.003^{* *}$ \\
\hline & & & $(0.000)$ & $(0.000)$ & $(0.019)$ & $(0.010)$ \\
\hline \multirow[t]{2}{*}{ AETC $_{t-1} \times$ Post Campaign } & & & $-0.043^{*}$ & $-0.046^{*}$ & $-0.062^{*}$ & $-0.069^{* * *}$ \\
\hline & & & $(0.082)$ & $(0.064)$ & $(0.057)$ & $(0.000)$ \\
\hline \multirow[t]{2}{*}{$\mathrm{SOE}_{\mathrm{t}-1}$} & & & & $-0.001^{* * *}$ & -0.0002 & $-0.002^{* * *}$ \\
\hline & & & & $(0.000)$ & $(0.673)$ & $(0.009)$ \\
\hline \multirow[t]{2}{*}{ Political Connection ${ }_{\mathrm{t}-1}$} & & & & -0.0001 & -0.0001 & -0.0001 \\
\hline & & & & $(0.563)$ & $(0.769)$ & $(0.777)$ \\
\hline \multirow[t]{2}{*}{$\mathrm{ROA}_{\mathrm{t}-1}$} & & & & & $-0.006^{* *}$ & $-0.005^{* * *}$ \\
\hline & & & & & $(0.019)$ & $(0.001)$ \\
\hline \multirow[t]{2}{*}{ Tobin’s Q $\mathrm{t}-1$} & & & & & $0.0003^{* * *}$ & -0.0001 \\
\hline & & & & & $(0.003)$ & $(0.436)$ \\
\hline \multirow[t]{2}{*}{ Leverage $_{t-1}$} & & & & & $-0.007^{* * *}$ & $-0.002^{* *}$ \\
\hline & & & & & $(0.000)$ & $(0.026)$ \\
\hline \multirow[t]{2}{*}{ Constant } & $0.003^{* * *}$ & $0.002^{* *}$ & $0.002^{* * *}$ & $0.003^{* * *}$ & $0.005^{* * *}$ & $0.008^{* * *}$ \\
\hline & $(0.006)$ & $(0.022)$ & $(0.000)$ & $(0.000)$ & $(0.000)$ & $(0.000)$ \\
\hline Industry fixed effects & Yes & Yes & Yes & Yes & Yes & No \\
\hline Province fixed effects & Yes & Yes & Yes & Yes & Yes & No \\
\hline Firm fixed effects & No & No & No & No & No & Yes \\
\hline$N$ & 7052 & 7052 & 7052 & 7052 & 7052 & 7052 \\
\hline$R^{2}$ & 0.073 & 0.079 & 0.081 & 0.086 & 0.117 & 0.642 \\
\hline
\end{tabular}


Panel B: High versus low corruption regions

\begin{tabular}{|c|c|c|c|c|}
\hline & $(1)$ & $(2)$ & (3) & (4) \\
\hline & $\begin{array}{c}\text { High } \\
\text { Corruption } \\
\end{array}$ & $\begin{array}{c}\text { High } \\
\text { Corruption } \\
\end{array}$ & $\begin{array}{c}\text { Low } \\
\text { Corruption } \\
\end{array}$ & $\begin{array}{c}\text { Low } \\
\text { Corruption } \\
\end{array}$ \\
\hline & Subsidies/Sales & Subsidies/Sales & Subsidies/Sales & Subsidies/Sales \\
\hline \multirow[t]{2}{*}{$\mathrm{R} \& \mathrm{D}$ Efficiency $\mathrm{t}-1$} & 0.002 & -0.0002 & $0.003^{* * *}$ & $0.002^{* *}$ \\
\hline & $(0.382)$ & $(0.806)$ & $(0.004)$ & $(0.018)$ \\
\hline \multirow{2}{*}{ AETC $_{\mathrm{t}-1}$} & & 0.066 & & $0.094^{* *}$ \\
\hline & & $(0.238)$ & & $(0.022)$ \\
\hline \multirow[t]{2}{*}{ Post Campaign } & & $0.001^{* *}$ & & $0.0004^{*}$ \\
\hline & & $(0.014)$ & & $(0.088)$ \\
\hline \multirow[t]{2}{*}{ R\&D Efficiency ${ }_{\mathrm{t}-1} \times$ Post Campaign } & & $0.010^{*}$ & & 0.003 \\
\hline & & $(0.053)$ & & $(0.111)$ \\
\hline \multirow[t]{2}{*}{ AETC $_{t-1} \times$ Post Campaign } & & $-0.125^{* *}$ & & -0.020 \\
\hline & & $(0.037)$ & & $(0.564)$ \\
\hline \multirow[t]{2}{*}{ Constant } & 0.002 & $0.004^{* *}$ & $0.003^{* * *}$ & $0.005^{* * *}$ \\
\hline & $(0.142)$ & $(0.049)$ & $(0.005)$ & $(0.000)$ \\
\hline Lagged firm controls & No & Yes & No & Yes \\
\hline Industry fixed effects & Yes & Yes & Yes & Yes \\
\hline Province fixed effects & Yes & Yes & Yes & Yes \\
\hline$N$ & 1408 & 1408 & 5644 & 5644 \\
\hline$R^{2}$ & 0.047 & 0.121 & 0.077 & 0.120 \\
\hline
\end{tabular}




\section{Table 6. Difference-in-Differences Analysis: Subsidies around government official departures}

This table conducts a difference-in-difference analysis of the change in R\&D subsidies received by firms with high and low R\&D efficiency (or high and low AETC) before and after the departures of the provincial technology bureau head. Subsidies are measured as the amount of R\&D subsidies a firm receives in a given year, divided by its annual revenue in that year. For each official departure event in year $t$, we use the three years before the departure year ( $t-1$, $t-2$, and $t-3)$ as the "before" window, and the three years after the departure year $(t+1, t+2$, and $t+3)$ as the "after" window. We sort firms by the average R\&D efficiency (or average AETC) during the three event years prior to the official departures. Firms with above (below) median efficiency (AETC) are classified as high- (low-) efficiency (AETC) firms. Panel A investigates the parallel trends assumption in the "before" window by comparing the yearone-year growth in R\&D subsidies (scaled by sales) received by the high and low R\&D efficiency (AETC) groups. Panel B (C) reports the difference-in-differences analysis for firms with high and low R\&D efficiency (AETC) prior to the official departure. Detailed variable definitions are found in the Appendix 1. *,**, *** indicate statistical significance at the $10 \%, 5 \%$, and $1 \%$ levels in a two-tailed test, respectively.

Panel A: Pre-trend annual growth in subsidies/sales

\begin{tabular}{lccc}
\hline & Event Year -3 & Event Year -2 & Event Year -1 \\
\hline High R\&D Efficiency & 0.032 & 0.285 & 0.074 \\
Low R\&D Efficiency & 0.270 & 0.530 & -0.135 \\
$t$-stat (High - Low) & -0.692 & -0.584 & 0.107 \\
\hline & Event Year -3 & Event Year -2 & Event Year -1 \\
\hline High AETC & 0.440 & 0.309 & -0.034 \\
Low AETC & 0.391 & 0.226 & 0.018 \\
$t$-stat (High - Low) & 0.157 & 0.279 & -0.366 \\
\hline
\end{tabular}

Panel B: Difference-in-differences test for firms with high and low R\&D efficiency

\begin{tabular}{lcccc}
\hline & Before & After & After - Before & $t$-stat \\
\hline High R\&D Efficiency & 0.0019 & 0.0050 & 0.0031 & $2.119^{* *}$ \\
Low R\&D Efficiency & 0.0018 & 0.0019 & 0.0001 & 0.157 \\
High - Low & 0.0001 & 0.0031 & 0.0030 & $2.030^{* *}$ \\
\hline
\end{tabular}

Panel C: Difference-in-differences test for firms with high and low AETC spending

\begin{tabular}{lcccc}
\hline & Before & After & After - Before & $t$-stat \\
\hline High AETC & 0.0043 & 0.0035 & 0.0008 & 0.046 \\
Low AETC & 0.0024 & 0.0047 & 0.0023 & $2.831^{* * *}$ \\
High - Low & 0.0019 & -0.0012 & -0.0031 & $-1.823^{*}$ \\
\hline
\end{tabular}




\section{Table 7. R\&D Subsidies around Government Official Departures: Panel regressions}

This table reports panel regression results of R\&D subsidies around the departure of provincial technology bureau heads. Subsidies are measured as the amount of R\&D subsidies a firm receives in a given year, divided by its annual revenue in that year. Post departure is an indicator variable that equals 1 for the three years after the official departure and 0 otherwise. Detailed definitions of all variables are found in the Appendix 1. Huber-White heteroskedasticityconsistent standard errors clustered by firm are used for all regressions. $p$-values are in parentheses. ${ }^{*}, * *, * * *$ indicates statistical significance at the $10 \%, 5 \%$, and $1 \%$ level, respectively.

\begin{tabular}{|c|c|c|c|c|c|c|}
\hline Dep Var = & $\begin{array}{c}(1) \\
\text { Subsidies } \\
\text { /Sales } \\
\end{array}$ & $\begin{array}{c}(2) \\
\text { Subsidies } \\
\text { /Sales } \\
\end{array}$ & $\begin{array}{c}\text { (3) } \\
\text { Subsidies } \\
\text { /Sales } \\
\end{array}$ & $\begin{array}{c}(4) \\
\text { Subsidies } \\
\text { /Sales } \\
\end{array}$ & $\begin{array}{c}\text { (5) } \\
\text { Subsidies } \\
\text { /Sales } \\
\end{array}$ & $\begin{array}{c}\text { (6) } \\
\text { Subsidies } \\
\text { /Sales } \\
\end{array}$ \\
\hline \multirow[t]{2}{*}{ R\&D Efficiency t-1 } & $0.003^{* * *}$ & $0.003^{* * *}$ & $0.002^{* *}$ & $0.003^{* *}$ & $0.002^{* *}$ & 0.001 \\
\hline & $(0.004)$ & $(0.003)$ & $(0.035)$ & $(0.031)$ & $(0.045)$ & $(0.249)$ \\
\hline \multirow[t]{2}{*}{ AETC/Sales $_{\mathrm{t}-1}$} & & $0.059^{* *}$ & $0.094^{* * *}$ & $0.090^{* * *}$ & $0.084^{* *}$ & $0.079^{* *}$ \\
\hline & & $(0.025)$ & $(0.005)$ & $(0.007)$ & $(0.016)$ & $(0.044)$ \\
\hline \multirow[t]{2}{*}{ Post Departure } & & -0.00004 & -0.0001 & -0.0001 & -0.0001 & 0.0004 \\
\hline & & $(0.866)$ & $(0.696)$ & $(0.696)$ & $(0.715)$ & $(0.110)$ \\
\hline \multirow[t]{2}{*}{ R\&D Efficiency $\mathrm{t}_{\mathrm{t}-1} \times$ Post Departure } & & & 0.001 & 0.001 & 0.001 & -0.002 \\
\hline & & & $(0.554)$ & $(0.504)$ & $(0.577)$ & $(0.217)$ \\
\hline \multirow{2}{*}{ AETC/Sales ${ }_{t-1} \times$ Post Departure } & & & $-0.070^{* *}$ & $-0.069^{* *}$ & $-0.055^{*}$ & $-0.078^{* * *}$ \\
\hline & & & $(0.019)$ & $(0.021)$ & $(0.088)$ & $(0.007)$ \\
\hline \multirow[t]{2}{*}{$\mathrm{SOE}_{\mathrm{t}-1}$} & & & & $-0.002^{* * *}$ & -0.000 & -0.002 \\
\hline & & & & $(0.001)$ & $(0.507)$ & $(0.136)$ \\
\hline \multirow[t]{2}{*}{ Political Connection ${ }_{t-1}$} & & & & -0.000 & -0.000 & -0.000 \\
\hline & & & & $(0.902)$ & $(0.952)$ & $(0.953)$ \\
\hline \multirow[t]{2}{*}{$\mathrm{ROA}_{\mathrm{t}-1}$} & & & & & $-0.006^{* *}$ & $-0.005^{* *}$ \\
\hline & & & & & $(0.014)$ & $(0.025)$ \\
\hline \multirow[t]{2}{*}{ Tobin’s $\mathrm{Q}_{\mathrm{t}-1}$} & & & & & $0.000^{* * * *}$ & -0.000 \\
\hline & & & & & $(0.006)$ & $(0.317)$ \\
\hline \multirow[t]{2}{*}{ Leverage $_{\mathrm{t}-1}$} & & & & & $-0.007^{* * *}$ & -0.001 \\
\hline & & & & & $(0.000)$ & $(0.424)$ \\
\hline \multirow[t]{2}{*}{ Constant } & $0.003^{* * *}$ & $0.003^{* * *}$ & $0.003^{* * *}$ & $0.003^{* * *}$ & $0.005^{* * *}$ & $0.001^{* *}$ \\
\hline & $(0.006)$ & $(0.005)$ & $(0.005)$ & $(0.000)$ & $(0.000)$ & $(0.032)$ \\
\hline Industry fixed effects & Yes & Yes & Yes & Yes & Yes & No \\
\hline Province fixed effects & Yes & Yes & Yes & Yes & Yes & No \\
\hline Firm fixed effects & No & No & No & No & No & Yes \\
\hline$N$ & 7052 & 7052 & 7052 & 7052 & 7052 & 7052 \\
\hline$R^{2}$ & 0.073 & 0.076 & 0.077 & 0.083 & 0.113 & 0.648 \\
\hline
\end{tabular}




\section{Table 8. Placebo Tests}

This table reports the results of our placebo tests, whereby we repeat the same regression analysis in Table 5, but pretend that the anti-corruption campaign began in 2009, or 2010, or 2011 instead of 2012. The empirical specification is identical to model (5) in Table 5. For each placebo year, we use three years before as the "before" window and three years after as the "after window". For instance, for the placebo year of 2009, 2006, 2007, and 2008 are used as the "before" window, and 2010, 2011, and 2012 as the "after" window. For brevity, only key coefficients are reported. Detailed variable definitions are found in the Appendix 1. Huber-White heteroskedasticity-consistent standard errors clustered by firm are used for all regressions. $p$-values are in parentheses. ${ }^{*}, * *, * * *$ indicate statistical significance at the $10 \%, 5 \%$, and $1 \%$ level, respectively.

\begin{tabular}{lcccc}
\hline & $(1)$ & $(2)$ & $(3)$ & $(4)$ \\
\hline & $\begin{array}{c}\text { Actual cutoff } \\
\text { year=2012 }\end{array}$ & $\begin{array}{c}\text { Placebo cutoff } \\
\text { year=2009 }\end{array}$ & $\begin{array}{c}\text { Placebo cutoff } \\
\text { year=2010 }\end{array}$ & $\begin{array}{c}\text { Placebo cutoff } \\
\text { year=2011 }\end{array}$ \\
\hline Dep Var $=$ & Subsidies/Sales & Subsidies/Sales & Subsidies/Sales & Subsidies/Sales \\
\hline R\&D Efficiencyt-1 & $0.002^{* *}$ & 0.001 & 0.001 & $0.001^{*}$ \\
& $(0.033)$ & $(0.433)$ & $(0.209)$ & $(0.066)$ \\
AETC ${ }_{\text {t-1 }}$ & $0.086^{* *}$ & $0.114^{*}$ & $0.088^{* *}$ & $0.088^{* *}$ \\
Post Campaign & $(0.014)$ & $(0.076)$ & $(0.027)$ & $(0.036)$ \\
& $0.001^{* *}$ & $0.001^{* * *}$ & $0.001^{* * *}$ & $0.001^{* * *}$ \\
R\&D Efficiency $\mathrm{t}-1 \times$ Post Campaign & $(0.023)$ & $(0.000)$ & $(0.002)$ & $(0.000)$ \\
& $0.006^{* *}$ & 0.002 & 0.003 & $0.004^{* *}$ \\
AETC ${ }_{\text {t-1 }}^{*}$ Post Campaign & $(0.019)$ & $(0.239)$ & $(0.253)$ & $(0.015)$ \\
& $-0.062^{*}$ & -0.067 & -0.015 & -0.055 \\
Constant & $(0.057)$ & $(0.253)$ & $(0.779)$ & $(0.200)$ \\
& $0.005^{* * *}$ & $0.004^{* * *}$ & $0.005^{* * *}$ & $0.004^{* * *}$ \\
Lagged firm controls & $(0.000)$ & $(0.000)$ & $(0.002)$ & $(0.000)$ \\
Industry fixed effects & Yes & Yes & Yes & Yes \\
Province fixed effects & Yes & Yes & Yes & Yes \\
\hline
\end{tabular}




\section{Table 9. R\&D Subsidies and Financial Constraints}

This table presents regression analysis of R\&D subsidies before and after the anti-corruption campaign, for firms with high or low financial constraints. Subsidies are measured as the amount of R\&D subsidies a firm receives in a given year, divided by its annual revenue in that year. The empirical specification is identical to model (5) in Table 5. We use two measures for financial constraints: firm size, and the Rajan-Zingales (RZ) measure of external financing dependency. Each year, we use the median firm enterprise value (market capitalization of equity plus the book value of total debt) to divide the sample into "Small firms" and "Large firms". We sort firms into those in industries with high and low external financing needs as described in the text. For brevity, only key coefficients are reported. Detailed independent variable definitions are found in the Appendix 1. Huber-White heteroskedasticity-consistent standard errors clustered by firm are used for all regressions. $p$-values are in parentheses. ${ }^{*}, * *,{ }^{* * *}$ indicate statistical significance at the $10 \%, 5 \%$, and $1 \%$ level, respectively.

\begin{tabular}{|c|c|c|c|c|}
\hline \multirow[b]{3}{*}{ Dep Var = } & (1) & (2) & (3) & (4) \\
\hline & Small Firms & Large Firms & $\begin{array}{l}\text { High External } \\
\text { Financing Needs }\end{array}$ & $\begin{array}{c}\text { Low External } \\
\text { Financing } \\
\text { Needs } \\
\end{array}$ \\
\hline & Subsidies/Sales & Subsidies/Sales & Subsidies/Sales & Subsidies/Sales \\
\hline \multirow[t]{2}{*}{ R\&D Efficiencyt } & $0.002^{*}$ & 0.001 & 0.001 & 0.002 \\
\hline & $(0.074)$ & $(0.382)$ & $(0.102)$ & $(0.105)$ \\
\hline \multirow[t]{2}{*}{ AETC $_{t-1}$} & $0.096^{* *}$ & $0.077^{*}$ & $0.078^{* *}$ & $0.100^{*}$ \\
\hline & $(0.023)$ & $(0.077)$ & $(0.037)$ & $(0.065)$ \\
\hline \multirow[t]{2}{*}{ Post Campaign } & 0.0004 & $0.001^{* *}$ & $0.001^{* *}$ & 0.0003 \\
\hline & $(0.365)$ & $(0.010)$ & $(0.022)$ & $(0.264)$ \\
\hline \multirow[t]{2}{*}{ R\&D Efficiency $\mathrm{t}-1_{1} \times$ Post Campaign } & $0.008^{* *}$ & 0.003 & $0.008^{* *}$ & 0.003 \\
\hline & $(0.043)$ & $(0.204)$ & $(0.031)$ & $(0.246)$ \\
\hline \multirow[t]{2}{*}{ AETC $_{t-1} \times$ Post Campaign } & $-0.078^{*}$ & 0.001 & $-0.078^{* *}$ & -0.038 \\
\hline & $(0.051)$ & $(0.983)$ & $(0.020)$ & $(0.532)$ \\
\hline \multirow[t]{2}{*}{ Constant } & $0.006^{* * *}$ & $0.003^{* * *}$ & $0.005^{* * *}$ & $0.005^{* * *}$ \\
\hline & $(0.000)$ & $(0.006)$ & $(0.000)$ & $(0.000)$ \\
\hline Lagged firm controls & Yes & Yes & Yes & Yes \\
\hline Industry fixed effects & Yes & Yes & Yes & Yes \\
\hline Province fixed effects & Yes & Yes & Yes & Yes \\
\hline$N$ & 3409 & 3643 & 3528 & 3524 \\
\hline$R^{2}$ & 0.109 & 0.141 & 0.113 & 0.134 \\
\hline
\end{tabular}




\section{Table 10. Subsidies and Future Innovation: Before and after the anti-corruption campaign}

This table investigates the relation between $\mathrm{R} \& \mathrm{D}$ subsidies and future innovation before and after the anti-corruption campaign. We present results using four measures of future innovation as the dependent variable. In Panel A, the dependent variable is Patent/Sales using U.S. patent data. In Panel B, the dependent variable is Relative Citation Strength using U.S. patent data. In Panel C, the dependent variable is Foreign Sales/Sales. In Panel D, the dependent variable is the firm's total factor productivity. For brevity, only key coefficients are reported. All variables are defined as in Appendix 1. In each regression, we include the lagged dependent variable to control for persistence. HuberWhite heteroskedasticity-consistent standard errors clustered by firm are used for all regressions. $p$-values are in parentheses. *, **, *** indicates statistical significance at the $10 \%, 5 \%$, and $1 \%$ level, respectively.

Panel A: U.S. patents

\begin{tabular}{lcccc}
\hline & $\begin{array}{c}(1) \\
\text { Patents/Sales } \\
\text { (U.S.) }\end{array}$ & $\begin{array}{c}\text { (2) } \\
\text { Patents/Sales } \\
\text { (U.S.) }\end{array}$ & $\begin{array}{c}\text { (3) } \\
\text { Patents/ Sales } \\
\text { (U.S.) }\end{array}$ & $\begin{array}{c}\text { Patents/ Sales } \\
\text { (U.S.) }\end{array}$ \\
\hline Patents/Sales (U.S.)t-1 & $0.502^{* * *}$ & $0.501^{* * *}$ & $0.497^{* * *}$ & $0.489^{* * *}$ \\
& $(0.000)$ & $(0.000)$ & $(0.000)$ & $(0.000)$ \\
Subsidies/Sales t-1 & $0.004^{* *}$ & 0.001 & -0.0002 & -0.0004 \\
& $(0.011)$ & $(0.598)$ & $(0.904)$ & $(0.764)$ \\
Subsidies/Sales t-1 $\times$ Post Campaign & & $0.005^{* * *}$ & $0.006^{* * *}$ & $0.006^{* * *}$ \\
& & $(0.005)$ & $(0.002)$ & $(0.003)$ \\
Constant & 0.00001 & 0.00001 & -0.0001 & -0.0002 \\
& $(0.687)$ & $(0.736)$ & $(0.824)$ & $(0.485)$ \\
Lagged firm controls & No & No & Yes & Yes \\
Industry fixed effects & No & No & No & Yes \\
Province fixed effects & No & No & No & Yes \\
Year fixed effects & Yes & Yes & Yes & Yes \\
$N$ & 8527 & 8527 & 8527 & 8527 \\
$R^{2}$ & 0.237 & 0.238 & 0.240 & 0.245 \\
\hline
\end{tabular}


Panel B: U.S. relative patent citation strength

\begin{tabular}{|c|c|c|c|c|}
\hline & $(1)$ & $(2)$ & (3) & (4) \\
\hline & $\begin{array}{l}\text { Relative Citation } \\
\text { Strength (U.S.) }\end{array}$ & $\begin{array}{l}\text { Relative Citation } \\
\text { Strength (U.S.) }\end{array}$ & $\begin{array}{l}\text { Relative Citation } \\
\text { Strength (U.S.) }\end{array}$ & $\begin{array}{l}\text { Relative Citation } \\
\text { Strength (U.S.) }\end{array}$ \\
\hline \multirow[t]{2}{*}{ Relative Citation Strength (U.S.) $)_{\mathrm{t}-1}$} & $0.182 * * *$ & $0.182^{* * *}$ & $0.179 * * *$ & $0.174 * * *$ \\
\hline & $(0.000)$ & $(0.000)$ & $(0.000)$ & $(0.004)$ \\
\hline \multirow{2}{*}{ Subsidies/Sales t-1 } & 0.191 & -0.290 & -0.328 & -0.440 \\
\hline & $(0.213)$ & $(0.263)$ & $(0.212)$ & $(0.150)$ \\
\hline \multirow{2}{*}{ Subsidies/Sales ${ }_{t-1} \times$ Post Campaign } & & $0.742^{* *}$ & $0.780^{* *}$ & $0.760^{* *}$ \\
\hline & & $(0.021)$ & $(0.016)$ & $(0.026)$ \\
\hline \multirow[t]{2}{*}{ Constant } & $0.013^{* *}$ & $0.014^{* *}$ & $-0.106 * * *$ & -0.124 \\
\hline & $(0.024)$ & $(0.016)$ & $(0.003)$ & $(0.142)$ \\
\hline Lagged firm controls & No & No & Yes & Yes \\
\hline Industry fixed effects & No & No & No & Yes \\
\hline Province fixed effects & No & No & No & Yes \\
\hline Year fixed effects & Yes & Yes & Yes & Yes \\
\hline$N$ & 8527 & 8527 & 8527 & 8527 \\
\hline$R^{2}$ & 0.046 & 0.047 & 0.050 & 0.055 \\
\hline
\end{tabular}

Panel C: Foreign sales

\begin{tabular}{lcccc}
\hline & $\begin{array}{c}(1) \\
\text { Foreign sales/ } \\
\text { Sales }\end{array}$ & $\begin{array}{c}(2) \\
\text { Foreign sales/ } \\
\text { Sales }\end{array}$ & $\begin{array}{c}(3) \\
\text { Foreign sales/ } \\
\text { Sales }\end{array}$ & $\begin{array}{c}\text { (4) } \\
\text { Foreign sales/ } \\
\text { Sales }\end{array}$ \\
\hline Foreign sales/ Sales $t-1$ & $0.905^{* * *}$ & $0.905^{* * *}$ & $0.904^{* * *}$ & $0.893^{* * *}$ \\
& $(0.000)$ & $(0.000)$ & $(0.000)$ & $(0.000)$ \\
Subsidies/Sales t-1 & 0.059 & -0.178 & -0.191 & -0.207 \\
& $(0.676)$ & $(0.174)$ & $(0.152)$ & $(0.129)$ \\
Subsidies/Sales t-1 $\times$ Post Campaign & & $0.760^{* *}$ & $0.771^{* *}$ & $0.798^{* *}$ \\
& & $(0.025)$ & $(0.023)$ & $(0.020)$ \\
Constant & -0.001 & -0.001 & $-0.037^{*}$ & $-0.058^{* *}$ \\
& $(0.742)$ & $(0.863)$ & $(0.098)$ & $(0.012)$ \\
Lagged firm controls & No & No & Yes & Yes \\
Industry fixed effects & No & No & No & Yes \\
Province fixed effects & No & No & No & Yes \\
Year fixed effects & Yes & Yes & Yes & Yes \\
$N$ & 7295 & 7295 & 7295 & 7295 \\
$R^{2}$ & 0.834 & 0.834 & 0.835 & 0.836 \\
\hline
\end{tabular}


Panel D: Productivity

\begin{tabular}{lcccc}
\hline & $(1)$ & $(2)$ & $(3)$ & $(4)$ \\
& TFP & TFP & TFP & TFP \\
\hline TFP $_{\mathrm{t}-1}$ & $0.734^{* * *}$ & $0.735^{* * *}$ & $0.738^{* * * *}$ & $0.731^{* * *}$ \\
& $(0.000)$ & $(0.000)$ & $(0.000)$ & $(0.000)$ \\
Subsidies/Sales $\mathrm{t}-1$ & $-0.650^{* *}$ & $-0.974^{* * *}$ & $-0.906^{* * *}$ & $-0.861^{* * *}$ \\
& $(0.025)$ & $(0.000)$ & $(0.002)$ & $(0.002)$ \\
Subsidies/Sales $\mathrm{t}-1 \times$ Post Campaign & & $1.045^{*}$ & $1.203^{*}$ & $1.274^{* * *}$ \\
& & $(0.086)$ & $(0.064)$ & $(0.040)$ \\
Constant & 0.004 & -0.004 & $-0.244^{* * *}$ & $-0.274^{* * *}$ \\
& $(0.726)$ & $(0.214)$ & $(0.006)$ & $(0.000)$ \\
Lagged firm controls & No & No & Yes & Yes \\
Industry fixed effects & No & No & No & Yes \\
Province fixed effects & No & No & No & Yes \\
Year fixed effects & Yes & Yes & Yes & Yes \\
$N$ & 7229 & 7229 & 7229 & 7229 \\
$R^{2}$ & 0.535 & 0.535 & 0.537 & 0.541 \\
\hline
\end{tabular}




\section{Table 11. Subsidies and Future Innovation: Around government official departures}

This table investigates the relation between R\&D subsidies and future innovation, around the departures of local officials. We present results using four measures of future innovation as the dependent variable. In Panel A, the dependent variable is Patent/Sales using U.S. patent data. In Panel B, the dependent variable is Relative Citation Strength using U.S. patent data. In Panel C, the dependent variable is Foreign Sales/Sales. In Panel D, the dependent variable is the firm's total factor productivity. For brevity, only key coefficients are reported. All variables are defined as in Appendix 1. In each regression, we include the lagged dependent variable to control for persistence. HuberWhite heteroskedasticity-consistent standard errors clustered by firm are used for all regressions. $p$-values are in parentheses. *, **, *** indicates statistical significance at the $10 \%, 5 \%$, and $1 \%$ level, respectively.

Panel A: U.S. patents

\begin{tabular}{lccc}
\hline & $(1)$ & $(2)$ & $(3)$ \\
& Patent/ Sales (U.S.) & Patent/ Sales (U.S.) & Patent/ Sales (U.S.) \\
\hline Patent/ Sales (U.S.)t-1 & $0.502^{* * *}$ & $0.499^{* * *}$ & $0.491^{* * *}$ \\
& $(0.000)$ & $(0.000)$ & $(0.000)$ \\
Subsidies/Sales ${ }_{\mathrm{t}-1}$ & $0.003^{* *}$ & 0.002 & 0.001 \\
& $(0.023)$ & $(0.101)$ & $(0.235)$ \\
Post Departure & $-0.00003^{*}$ & -0.00003 & -0.00002 \\
& $(0.082)$ & $(0.129)$ & $(0.407)$ \\
Subsidies/Sales $\mathrm{t}-1 \times$ Post Departure & $0.004^{* *}$ & $0.004^{* *}$ & $0.004^{* *}$ \\
& $(0.032)$ & $(0.026)$ & $(0.016)$ \\
Constant & 0.00001 & -0.0001 & -0.0002 \\
& $(0.682)$ & $(0.764)$ & $(0.455)$ \\
Lagged firm controls & No & Yes & Yes \\
Industry fixed effects & No & No & Yes \\
Province fixed effects & No & No & Yes \\
Year fixed effects & Yes & Yes & Yes \\
$N$ & 8527 & 8527 & 8527 \\
$R^{2}$ & 0.238 & 0.240 & 0.245 \\
\hline
\end{tabular}


Panel B. U.S. relative patent citation strength

\begin{tabular}{lccc}
\hline & $\begin{array}{c}(1) \\
\text { Relative Citation } \\
\text { Strength (U.S.) }\end{array}$ & $\begin{array}{c}(2) \\
\text { Relative Citation } \\
\text { Strength (U.S.) }\end{array}$ & $\begin{array}{c}(3) \\
\text { Relative Citation } \\
\text { Strength (U.S.) }\end{array}$ \\
\hline Relative Citation Strength (U.S.)t-1 & $0.182^{* * *}$ & $0.179^{* * *}$ & $0.173^{* * *}$ \\
& $(0.000)$ & $(0.000)$ & $(0.000)$ \\
Subsidies/Sales t-1 & -0.021 & -0.028 & -0.172 \\
& $(0.915)$ & $(0.888)$ & $(0.404)$ \\
Post Departure & $-0.005^{*}$ & $-0.005^{*}$ & -0.004 \\
& $(0.076)$ & $(0.099)$ & $(0.260)$ \\
Subsidies/Sales t-1 $\times$ Post Departure & $0.478^{*}$ & $0.472^{*}$ & $0.514^{*}$ \\
& $(0.093)$ & $(0.097)$ & $(0.077)$ \\
Constant & $0.015^{* *}$ & $-0.108^{* * *}$ & $-0.126^{* * *}$ \\
& $(0.012)$ & $(0.003)$ & $(0.001)$ \\
Lagged firm controls & No & Yes & Yes \\
Industry fixed effects & No & No & Yes \\
Province fixed effects & No & No & Yes \\
Year fixed effects & Yes & Yes & Yes \\
$N$ & 8527 & 8527 & 8527 \\
$R^{2}$ & 0.047 & 0.050 & 0.054 \\
\hline
\end{tabular}

Panel C. Foreign sales

\begin{tabular}{lccc}
\hline & $(1)$ & $(2)$ & $(3)$ \\
& Foreign Sales/ Sales & Foreign Sales/ Sales & Foreign Sales/ Sales \\
\hline Foreign Sales/ Salest-1 & $0.905^{* * *}$ & $0.904^{* * *}$ & $0.893^{* * *}$ \\
& $(0.000)$ & $(0.000)$ & $(0.000)$ \\
Subsidies/Sales t-1 & -0.079 & -0.101 & -0.120 \\
Post Departure & $(0.581)$ & $(0.489)$ & $(0.418)$ \\
& 0.002 & 0.002 & 0.003 \\
Subsidies/Sales t-1 $^{*}$ Post Departure & $(0.349)$ & $(0.342)$ & $(0.254)$ \\
& $0.599^{*}$ & $0.633^{*}$ & $0.660^{*}$ \\
Constant & $(0.082)$ & $(0.067)$ & $(0.058)$ \\
& -0.003 & -0.038 & $-0.057^{* *}$ \\
Lagged firm controls & $(0.455)$ & $(0.142)$ & $(0.038)$ \\
Industry fixed effects & No & Yes & Yes \\
Province fixed effects & No & No & Yes \\
Year fixed effects & No & No & Yes \\
$N$ & Yes & Yes & Yes \\
$R^{2}$ & 7295 & 7295 & 7295 \\
\hline
\end{tabular}


Panel D: Productivity

\begin{tabular}{lccc}
\hline & $(1)$ & $(2)$ & $(3)$ \\
& TFP & TFP & TFP \\
\hline $\mathrm{TFP}_{\mathrm{t}-1}$ & $0.734^{* * *}$ & $0.738^{* * *}$ & $0.731^{* * *}$ \\
& $(0.000)$ & $(0.000)$ & $(0.000)$ \\
Subsidies/Sales $\mathrm{t}^{*} \mathrm{x}$ & $-0.748^{* * *}$ & $-0.659^{* * *}$ & $-0.653^{* *}$ \\
& $(0.008)$ & $(0.009)$ & $(0.026)$ \\
Post Departure & -0.001 & -0.002 & 0.002 \\
& $(0.715)$ & $(0.579)$ & $(0.535)$ \\
Subsidies/Sales $\mathrm{t}-1 \times$ Post Departure & $0.407^{*}$ & 0.508 & $0.757^{* * *}$ \\
& $(0.067)$ & $(0.136)$ & $(0.000)$ \\
Constant & $0.004^{* *}$ & $-0.244^{*}$ & $-0.273^{* *}$ \\
& $(0.036)$ & $(0.069)$ & $(0.021)$ \\
Lagged firm controls & No & No & Yes \\
Industry fixed effects & No & No & No \\
Province fixed effects & No & No & No \\
Year fixed effects & Yes & Yes & Yes \\
$N$ & 7229 & 7229 & 7229 \\
$R^{2}$ & 0.535 & 0.537 & 0.541 \\
\hline
\end{tabular}




\section{Appendix 1 - Variable Definitions}

Age: The number of years between a company's establishment and the year of the observation.

Business in Other Regions: The number of geographical regions within a firm derives revenue from. Chinese provinces are grouped into eight geographic regions: North (华北), South (华南), Middle (华中), East (华东), North-East (东北), North-West (西北), South-West (西南), and Hong Kong/Macau/Taiwan （港, 澳, 台). Foreign countries are coded as one separate region.

ETC/Sales (AETC/Sales): ETC stands for firms' Entertainment and Travel Costs, reported in firm's annual statements. ETC/Sales (AETC/Sales) is a firm's amount of ETC (Abnormal ETC) spending, divided by its annual revenue. The AETC is the Abnormal Entertainment and Travel Costs, calculated as the residual of Equation (1) in the text.

Foreign Sales/Sales: A firms' overseas revenue divided by total revenue in a given year.

Intangible Assets/Assets: The book value of a firm's intangible assets divided by the book value of its total assets.

Leverage: A firms’ book value of total liabilities divided by its book value of total assets.

Patents/Sales: The number of Chinese invention patent applications filed by a firm in a given year that are ultimately granted through the end of 2017, divided by its revenue (measured in millions of RMB) in that year.

Patents/Sales (U.S.): Similarly defined as Patents/Sales, but instead using a firm’s U.S. patents.

Political Connections: An indicator variable if a company's CEO or chairman of the board has been a government official in the past. These are determined from CEO and chairman profiles are obtained from company annual statements.

Post Campaign: An indicator variable that equals 1 for the years 2013, 2014, and 2015, the three years after the beginning of the anti-corruption campaign that began in 2012.

Post Departure: An indicator variable that equals 1 for the three years after a provincial technology bureau official's departure from his/her post.

Relative Citation Strength (U.S.): The number of U.S. patent citations through April 30, 2018 per U.S. patent applied for in year $t$ by firm $i$ (that was ultimately granted by the end of 2017), divided by the number of citations per patent received over the same period by all U.S. patents applied for in year $t$ (that was also ultimately granted by the end of 2017) in the same 4-digit technological class according to the Combined Patent Classification (CPC) code.

Return on Assets: A firm's net income in a given year divided by its book value of total assets at the beginning of the year of the observation.

R\&D Efficiency: A firm's R\&D efficiency, calculated as Equation (2) in the paper as the ratio of the number of Chinese patents applied by a firm in a given year that were ultimately approved, divided by a capitalized measure of R\&D expenditure measured in millions of RMB. 
R\&D/Sales: A firm's R\&D expenditure in a year divided by its revenues in the same year.

RZ (Rajan-Zingales) measure of external financing needs: The average across all the sample firms in the firm's industry (using the Chinese Securities Regulatory Commission's two-digit industry classification codes) of the ratio of capital expenditures in a given year minus cash flow from operations in the same year, divided by capital expenditure.

Size: The book value of a firm's total assets at the beginning of the observation year, in millions of RMB.

Small Firms: Each year, firms whose enterprise value (market capitalization of equity plus the book value of total debt) is below the sample median enterprise value are classified as small firms.

Subsidies/Sales: The amount of R\&D subsidies a firm receives in a given year, divided by its annual revenue in that year.

SOE: An indicator variable if a company's largest ultimate shareholder, as disclosed in its annual statements, is a government entity.

Tobin's Q: A firm's market value of equity (average share price in a given year multiplied by its average number of shares outstanding) plus its book value of debt, divided by the book value of its total assets.

Total Factor Productivity (TFP): We follow Giannetti, Liao, and Yu (2011) and calculate the TFP of Chinese firms as the residual from the following cross-sectional regression which is estimated annually for each industry (using the Chinese Securities Regulatory Commission's two-digit industry classification codes):

$$
y_{i t}=\alpha_{i t}+\beta_{i t} l_{i t}+\gamma_{i t} k_{i t}+\delta_{i t} m_{i t}+\varepsilon_{i t}
$$

where $y_{i t}$ is the natural log of one plus firm's $i$ 's total revenue (in RMB) in year $t ; l_{i t}$ is the natural $\log$ of one plus firm $i$ 's employment (in persons) in year $t ; k_{i t}$ is the natural $\log$ of one plus firm $i$ 's total assets (in RMB) in year $t$; and $m_{i t}$ the natural $\log$ of one plus firm $i$ 's total expenditures (in RMB) on labor and capital goods in year $t$. 